\title{
G semestem \\ Differential Brain and Cerebrospinal Fluid Proteomic Responses To Acute Prenatal Endotoxin Exposure
}

\section{Tik Muk}

University of Copenhagen: Kobenhavns Universitet

\section{Allan Stensballe}

Aalborg University: Aalborg Universitet

\section{Oksana Dmytriyeva}

University of Copenhagen: Kobenhavns Universitet

\section{Anders Brunse}

University of Copenhagen: Kobenhavns Universitet

\section{Ping-Ping Jiang}

University of Copenhagen: Kobenhavns Universitet

\section{Thomas Thymann}

University of Copenhagen: Kobenhavns Universitet

\section{Per Torp Sangild}

University of Copenhagen: Kobenhavns Universitet

Stanislava Pankratova ( $\sim$ stasya@sund.ku.dk)

Kobenhavns Universitet https://orcid.org/0000-0002-5406-5163

\section{Research}

Keywords: Neurodevelopment, Inflammation, Cerebrospinal fluid, Preterm pig, Hippocampus, Chorioamnionitis

Posted Date: October 12th, 2021

DOl: https://doi.org/10.21203/rs.3.rs-910516/v1

License: (c) This work is licensed under a Creative Commons Attribution 4.0 International License. Read Full License

Version of Record: A version of this preprint was published at Molecular Neurobiology on January 21 st, 2022. See the published version at https://doi.org/10.1007/s12035-022-02753-2. 


\section{Abstract \\ Background}

Chorioamnionitis (CA) is a risk factor for preterm birth and is associated with neurodevelopmental delay and cognitive disorders. Prenatal inflammation-induced brain injury may resolve during the immediate postnatal period, which is a time of rapid metabolic and brain remodeling. Cerebrospinal fluid (CSF) collected at birth may be a critical source of predictive biomarkers. Using pigs as a model of preterm infants exposed to CA, we hypothesized that prenatal lipopolysaccharide (LPS) exposure induces proteome changes in the CSF and brain both at birth and later.

\section{Methods}

Fetal piglets (103 days gestation of the full-term 117 days) were administered intra-amniotic (IA) lipopolysaccharide (LPS) 3 days before preterm delivery by caesarian section. CSF and brain tissue were collected on postnatal Days 1 and 5 (P1 and P5). CSF and hippocampal proteins were profiled by LCMS-based quantitative proteomics. Neuroinflammatory responses in the cerebral cortex, periventricular white matter and hippocampus were evaluated by immunohistochemistry, and gene expression was evaluated by qPCR.

\section{Results}

Pigs exposed to LPS in utero showed changes in CSF protein levels at birth but not at P5. Complement protein $\mathrm{C} 3$, hemopexin, vasointestinal peptide, carboxypeptidase $\mathrm{N}$ subunit 2, ITIH1 and plasminogen expression was upregulated in the CSF, while the expression of proteins associated with axon growth and synaptic functions (FGFR1, BASP1, HSPD1, UBER2N, and RCN2), adhesion (Talin1), and neuronal survival (Atox1) was downregulated. Microglia, but not astrocytes, were activated by LPS at P5 in the hippocampus but not in other brain regions. At this time, marginal increases in complement protein $C 3$, $L B P$, Hif1a, Basp1, Minpp1 and FGFR1 transcription indicated hippocampal proinflammatory responses.

\section{Conclusion}

A brief period of prenatal endotoxin exposure induces proteome changes in the CSF and brain at birth, but most changes resolve a few days later. The developing hippocampus has high neuronal plasticity in response to perinatal inflammation. Changes in CSF protein expression at birth may help to predict later structural brain damage in preterm infants exposed to variable types and durations of CA-related inflammation in utero.

\section{Introduction}


Chorioamnionitis (CA) and the associated intrauterine inflammation are risk factors for spontaneous preterm delivery (Adams-Chapman \& Stoll, 2006). CA is associated with $40-70 \%$ of preterm births (Jain et al., 2021) and leads to cerebral lesions and neurodevelopmental delay (Adams-Chapman \& Stoll, 2006); however, the links are not clear and may depend on the time, duration and type of perinatal inflammation. CA may induce lesions in white matter, such as altered vascular microstructure and periventricular hemorrhage, as well as lesions in grey matter, such as increased neuronal apoptosis, abnormal neuronal circuit formation and cognitive impairments (Versland et al., 2006; Nasef et al., 2013; Strackx et al., 2015; Anblagan et al., 2016). Recent data also suggested that neuropsychiatric disorders, such as autism spectrum disorder and schizophrenia, might have a neurodevelopmental origin and be linked to feto-maternal inflammation (Pinelli \& Zwaigenbaum, 2008; Hagberg et al., 2015; Estes \& McAllister, 2016; Thorell et al., 2020). CA-related brain lesions may be mediated in spatiotemporal ways by several mechanisms, including transport of cytotoxic molecules across the blood-brain barrier (BBB), transient activation of microglia accompanied by release of proinflammatory cytokines and reactive oxygen species, arrest of preoligodendrocyte maturation followed by hypomyelination, reduced synaptic density, impaired neurogenesis and cell death (Burd et al., 2012; Back \& Rosenberg, 2014; Strackx et al., 2015; Penn et al., 2016; Gussenhoven et al., 2018). In particular, the hippocampus, a brain region centrally involved in memory and cognitive processes, was shown to be affected in various preclinical models of CA (Gavilanes et al., 2009; Bilbo \& Schwarz, 2012; Gussenhoven et al., 2018), and it has a smaller volume in preterm infants exposed to CA (Hatfield et al., 2011).

The type and severity of inflammation-induced abnormalities in the fetal brain are critically dependent on the type, timing and duration of in utero inflammation, since distinct neurodevelopmental programs are affected at different gestational ages (Meyer et al., 2006; Matcovitch-Natan et al., 2016; Gussenhoven et al., 2018). Thus, the diagnosis and characterization of CA-related brain pathophysiology is difficult. Evidence from numerous experimental animal studies suggests that feto-maternal inflammation induces an imbalance in endogenous neurotrophic factors and immune molecules that impact the course of brain development (Urakubo et al., 2001; Adams-Chapman \& Stoll, 2006; Bilbo \& Schwarz, 2012; Antonson et al., 2019). However, the underlying mechanisms and optimal biomarkers of postnatal CA-induced brain injury remain unknown.

Cerebrospinal fluid (CSF) components have emerged as important mediators of extracellular signaling and are centrally involved in the maintenance of brain development and homeostasis (Reiber, 2001; Sawamoto et al., 2006; Lehtinen et al., 2011; Kaiser \& Bryja, 2020). In addition to ependymal cells, that line the cerebral ventricles and regulate the concentration of active peptides in the CSF,neural progenitor cells extend processes into the ventricles and directly contact the CSF (reviewed in (Ziegler et al., 2015)). CSF, which is cycled throughout the brain perivascular space, provides a fluid for the glymphatic system and is responsible for the clearance of brain parenchyma (Rasmussen et al., 2018). Therefore, CSF not only carries plasma proteins but also is indicative of the endogenous brain microenvironment and is thereby an important source of brain pathophysiological markers (Begcevic et al., 2016). The protein composition of CSF changes throughout an individual's lifetime, and transient changes in the levels of growth factors (e.g., IGFs, FGF2, NGF, and TGF-a) occur during the fetal and perinatal periods (Zappaterra 
et al., 2007; Greenwood et al., 2008; Lun et al., 2015; Ziegler et al., 2015; Kaiser \& Bryja, 2020). Importantly, the total CSF protein levels are higher in preterm vs. term neonates, while the white blood cell counts do not differ (Srinivasan et al., 2012). We previously documented rapid changes in CSF protein composition in response to neonatal infection in preterm pigs (Muk et al., 2019). Furthermore, we described how the brain differs both structurally and functionally between preterm and term pigs (Andersen et al., 2016; Bergstrom et al., 2016; Holme Nielsen et al., 2018; Obelitz-Ryom et al., 2019) and how the brain responds to different diets (Andersen et al., 2017; Obelitz-Ryom et al., 2018; Andersen et al., 2019) and infections (Brunse et al., 2019) in the days and weeks after preterm birth. While the screening of CSF biomarkers is a promising tool to predict neuropathology in human adults (Begcevic et al., 2016), little effort has been made to elucidate the CSF protein composition in preterm neonates exposed to CA. We therefore used preterm pigs exposed to endotoxin in utero for a relatively short period before birth (3 days) to investigate the effects on the CSF and brain proteome as well as the potential to use CSF proteins as biomarkers of postnatal structural brain responses.

\section{Materials And Methods}

\section{Animal experimentation and tissue collection}

The detailed design of the in vivo study is shown in Fig. 1A using BioRender (San Francisco Bay Area, USA). Briefly, 54 fetuses from three pregnant sows (Large White $\times$ Danish Landrace $\times$ Duroc) were randomly allocated to receive an intra-amniotic injection of either $1 \mathrm{mg}$ LPS/fetus (Escherichia coli, serotype 055:B5; Sigma-Aldrich, Copenhagen, Denmark) or control (saline or no injection; CON) at 103 days of gestation (E103). After 3 days, at E106, which corresponds to $90 \%$ gestation (full-term birth is $117 \pm 2$ days), the fetuses were delivered by cesarean section and randomly allocated either to be sacrificed shortly after delivery at Day $1(P 1 ; C O N n=14$, LPS $n=16)$ or reared for 5 days $(P 5 ; n=12$ for each group) as previously described (Muk et al., 2020). The changes in systemic inflammatory marker levels and blood cell counts were previously published (Nguyen et al., 2018). Immediately after euthanasia, CSF samples were collected by suboccipital puncture and frozen at $-80^{\circ} \mathrm{C}$ for proteomics analysis. A small aliquot of CSF sample was used for counting leucocytes. The dissected brain was separated into hemispheres: the right hemisphere was immersed in $4 \%$ paraformaldehyde (PFA), and the isolated hippocampus from the left hemisphere was snap frozen and stored at $-80^{\circ} \mathrm{C}$ for further analysis.

The levels of IL-8 in liver and spleen samples were measured with porcine DuoSet ELISA kits (R\&D Systems, Minneapolis, MN, USA) according to the manufacturer's protocol.

\section{Proteomics analysis}

The CSF samples were centrifuged at $1000 \times \mathrm{g}$ for $5 \mathrm{~min}$ to remove cell debris. Hippocampal tissue was homogenized in chilled homogenization buffer ( $5 \%$ sodium deoxycholate, $50 \mathrm{mM}$ triethyl ammonium bicarbonate, $\mathrm{pH}$ 8.5). The protein concentration was determined by UV spectrometry (NanoDrop 2000; Thermo Scientific, MA, USA). A PVDF membrane-based proteomic sample processing method was used for on-membrane tryptic digestion using a multiscreen filtration plate basically following the procedure 
described by (Berger et al., 2015). Briefly, the total CSF and hippocampal proteins (15 $\mu \mathrm{g})$ were diluted with saturated urea followed by a reduction with TCEP $(10 \mathrm{mM})$ and alkylation ( $50 \mathrm{mM}$ chloroacetamide). The samples were loaded on primed membranes and washed twice with $300 \mu \mathrm{l}$ of $50 \mathrm{mM}$ TEAB buffer. Digestion buffer $(100 \mu \mathrm{l}, 5 \%$ TFE (v/v), $5 \%$ ACN (v/v), trypsin 1:60 in $50 \mathrm{mM}$ TEAB) was added to each sample and incubated overnight at $37^{\circ} \mathrm{C}$ in an air incubator with high humidity. Tryptic peptides were transferred to a collection tube, and the remaining peptides were extracted with $150 \mu$ I TEAB buffer supplemented with $40 \%$ acetonitrile (ACN, v/v) and $0.1 \%$ formic acid (FA; $/ \mathrm{v})$. The pooled extracts were dried by vacuum centrifugation and resuspended in loading solvent $(2 \% A C N, 0.1 \%$ trifluoroacetic acid, $0.1 \%$ FA in Milli-Q water) before being loaded into the LC-MS system.

The individual CSF and hippocampal samples were randomized and sequenced on a hybrid trapped ion mobility spectrometry (TIMS) quadrupole time of flight (QTOF) mass spectrometer, i.e., timsTOF in timsoff mode (Bruker Daltonics, Bremen, Germany) coupled to a modified nanoelectrospray ion source (CaptiveSpray, Bruker Daltonics) with an applied voltage of $1800 \mathrm{~V}$. Liquid chromatography was performed using a Dionex RSCL Proflow UHPLC setup (Dionex, Thermo Scientific, Waltham, United States). Each sample was loaded onto a 2-cm reverse-phase C18-material trapping column and separated on a 75-cm analytical column (both from Acclaim PepMap100, Thermo Scientific). The liquid phase consisted of $96 \%$ solvent $A(0.1 \% \mathrm{FA})$ and $4 \%$ solvent $B(0.1 \% \mathrm{FA}$ in $\mathrm{ACN})$ at a flow rate of 300 $\mathrm{nl} / \mathrm{min}$. The peptides were eluted from the column by increasing concentrations of solvent $\mathrm{B}$ (to $8 \%$ and subsequently to $30 \%$ ) with a 35 -min ramp gradient and introduced into the mass spectrometer by a Captivespray emitter for electrospray ionization (Bruker; Germany). The mass spectrometer was operated in positive mode with data-dependent acquisition (DDA), alternating between survey spectra and isolation/fragmentation spectra. All the samples were analyzed in duplicate in a random order.

\section{Immunohistochemistry (IHC) and image analysis}

Based on the pig brain atlas (Felix et al., 1999), a predefined brain region including the hippocampus was embedded in paraffin and serially sliced into 7- $\mu \mathrm{m}$ coronal sections. IHC was assessed with antibodies to glial fibrillary acidic protein (GFAP; 1:800, Dako, Denmark) and ionized calcium-binding adapter molecule 1 (Iba1; 1:1000, ab5076, Abcam, Denmark) using 3-4 sections per animal. Tissue deparaffanization and labeling were performed as described previously (Sun et al., 2018). Four images per section from the cortical region, periventricular white matter (PVWM), and hippocampus were captured using CAST-GRID software (Olympus Denmark A/S) and quantified with image analysis software PlabApp (Protein Laboratory, Denmark). For each staining, recorded images were adjusted to the same threshold level, and the positively immunostained area was quantified and expressed as an average percentage. An observer blinded to the study groups performed all the histological assessments. To minimize staining differences, all the sections were stained at the same time using the same preparations.

\section{Gene expression analysis by real-time quantitative PCR}

Hippocampal samples were homogenized in QIAzol lysis reagent (Qiagen, Copenhagen, Denmark), and total RNA was isolated using an RNeasy Lipid Tissue Mini Kit (Qiagen, Copenhagen, Denmark) and 
converted to cDNA with a High-Capacity cDNA Reverse Transcription Kit (Thermo Fisher, Waltham, MA, USA). Quantitative real-time PCR analysis of the expression of selected genes (see Supplementary Table S1 for primer list) was performed in duplicate using the LightCycler 480 SYBR Green I Master kit on a LightCycler 480 (both Roche, Basel, Switzerland). The gene expression level was normalized to hypoxanthine-guanine phosphoribosyltransferase 1 (HPRT1), and the relative expression was analyzed using the ${ }^{-}{ }_{\triangle} \triangle \mathrm{CT}$ method.

\section{Data analysis and statistics}

Proteomic data were searched with MaxQuant ( $v$ 1.6.2.3), using default settings, against the UniProt Sus scrofa reference Proteome (UPID000008227) using carbamidomethylcystine (fixed mod) and oxidized methionine (variable mod). Initial processing was performed in Pereus (v.1.6.5.0 for CSF and v. 1.6.2.3 for hippocampus). All the statistics were performed in $\mathrm{R}$ (version 4.0.2, Vienna, Austria), and graphs were generated with R studio (RStudio, Boston, MA, USA) and GraphPad Prism version 8.0.2 software (GraphPad Software, San Diego, CA). For proteomic analysis, the data were sorted into the effect protein group and exposure protein group using the criteria that an effect protein was detected in at least $80 \%$ of all the samples of each treatment group and an exposure protein was detected in less than $20 \%$ of all samples in one treatment group and above $80 \%$ of all samples in another group. Significant differences between the treatment groups were identified by a linear mixed effect model using treatment and sex as the fixed factors and litter as a random factor, and the analyses were conducted with the Ime 4 and multcomp packages. To control the type I error, $\mathrm{p}$ value tests were further adjusted into $q$ values with Benjamini-Hochberg (BH)-adjusted false discovery rate (FDR, $\mathrm{a}=0.1)$. A threshold of adjusted $p \leq 0.1$ was set to identify effect differentially expressed proteins (DEPS) between groups. Significant exposure DEPs between groups were identified by Fisher's exact test, and a threshold of $p \leq 0.05$ was used to identify exposure DEPs between groups. qPCR data were analyzed using a linear mixed-effects model followed by Tukey's post hoc multiple comparison test, with treatment and sex as fixed factors and litter as a random factor. A threshold of $p<0.05$ was used to identify significantly regulated genes between groups. A Venn diagram was generated in $\mathrm{R}$ by the VennDiagram package.

\section{Results}

\section{Prenatal LPS exposure marginally alters the CSF protein profile at birth}

The study design of the experiment is illustrated in Fig. 1A. Compared to CON, intraamniotic (IA) exposure to LPS did not alter the number of infiltrating leucocytes in the CSF on P1 (Fig. 1B), suggesting that the BBB was intact, which is consistent with our previous observations (Nguyen et al., 2018). Moreover, the levels of IL-8 in the liver and spleen tissues were not different between the CON and LPS groups on both P1 and P5 (Fig. 1C). Of 1398 CSF proteins identified and annotated after statistical filtration, 953 and 981 proteins were detected in at least one piglet on P1 and P5, respectively. Annotated proteins were further sorted into the effect and exposure protein groups. Compared with the data obtained in our previous 
study (Muk et al., 2020), the CSF proteome had partial overlap with the corresponding plasma proteome (44.3\% overlap of total annotated proteins), indicating that ( $i$ ) at least some of the identified CSF proteins were produced locally in the brain and (ii) CSF protein composition underwent time-dependent dynamic changes.

IA LPS exposure affected nine CSF DEPs on P1 and only one DEP on P5 (Supplementary Table S2). Compared with the CON group, the LPS group had five proteins that were significantly upregulated ( $q \leq$ 0.05), including $C 3$, complement factor $B(C F B)$, hemopexin (HPX), plasminogen and inter-alpha-trypsin inhibitor heavy chain 1 (ITIH1) ( $q \leq 0.1$ for the latter), at P1 (Fig. 2A, B); these proteins have functions related to the immune response and mimic the similar trend of these protein levels in the plasma (Muk et al., 2020). Moreover, the CSF levels of fibroblast growth factor receptor 1 (FGFR1) and brain acid soluble protein 1 (BASP1) were significantly downregulated at P1 but recovered to CON levels at P5 (Fig. 2C).

Moreover, an additional eight proteins were identified as 'exposure DEPs' on P1, and these proteins were detected in the P1 group at more than $80 \%$ and less than $20 \%$ and only one of them (CPN2) overlapped with plasma DEPs (Fig. 3A; Supplementary Table S3). Among these eight CSF DEPs, six proteins (Talin1, Atox1, Aminoacylase, HSPD1, UBEN2N and RCN2) were transiently undetected at P1 but returned to CON levels at P5 (Fig. 3B-G). In contrast, two DEPs, VIP and CPN2, showed the reversed trend, e.g., they were absent in the CON group at P1, while at P5, their levels were similar to the LPS levels (Fig. $3 \mathrm{H}-\mathrm{I})$. These results are consistent with our clinical observations and plasma proteome profile results from previous studies (Nguyen et al., 2018; Muk et al., 2020). Our results suggest that prenatal LPS exposure marginally alters the CSF protein profile at birth, but most of the effects resolved after a few days postnatally (neonatal adaptation phase). Overall, our results revealed plasma-shared and CSF-specific transient changes in protein levels in perinatal CSF in response to intrauterine LPS exposure.

\section{Antenatal inflammation induced hippocampal microgliosis and altered the protein profile at P5}

Compared with the CON group, a significantly higher level of Iba1-ir was observed in the hippocampus of LPS-treated pigs at P5 $(p<0.05)$ but not at P1. Moreover, a decrease in Iba1-ir at P1 vs. P5 was observed in the PVWM in both the CON $(p<0.05)$ and LPS groups $(p<0.01)$ over time. A similar trend was observed in the hippocampus of the CON group $(p<0.01)$, whereas for the LPS group, the time-dependent decrease in Iba1-ir was not significant (Fig. 4A, C). No difference between treatment groups was observed for GFAP labeling in all the analyzed regions and across time points, although the developmental increase in GFAP immunoreactivity was recorded within PVWM alone, suggesting ongoing gliogenesis in this region (Fig. 4B).

Given that microglial activation was observed only at P5 and was limited to hippocampal formation, we next sought to investigate the molecular changes in the hippocampus at this time point. MS-based proteomics of hippocampal tissue identified a total of 4038 quantifiable proteins. While 682 proteins showed a $p$ value $<0.05$, only three proteins remained significant after FDR adjustment (Supplementary Table S4). Among these proteins, the expression of both elastin and multiple inositol polyphosphate 
phosphatase 1 (MINPP1) was downregulated in the LPS group, and the expression of prickle homolog 2 (PRICKLE2) was upregulated in the LPS group (Fig. 5A; Supplementary Table S4). In addition, the expression of three hippocampal proteins, melanoma inhibitor protein 3 (MIA3), claudin 11 (CLDN11) and plasmolipin (PLLP), was upregulated 3-5-fold in the hippocampus at P5, but the adjusted $p$ value did not pass the threshold criteria (Fig. 5B).

\section{IA LPS transiently changed the expression of immunomodulatory and neuroplasticity genes in the hippocampus}

To further validate the expression of selected hippocampal targets by an alternative approach, reverse transcription qPCR was performed. Compared with those in the CON group, the expression levels of Elastin, CLND11, MIA3, PLLP and PRICKLE2 were unaltered in the LPS group over time (data not shown), whereas the hippocampal expression levels of MINPP1 and FGFR1 were significantly upregulated at P5 (Fig. 6A), probably due to a compensatory response. In addition, the expression of $B A S P 1$ tended to decrease at P1 $(p=0.07)$ but increased at P5 $(p<0.05)$ in the LPS group. The expression of several other selected genes with immunomodulatory functions was significantly upregulated in the LPS group, including $\angle B P$ (Lipopolysaccharide-binding protein), S100A9, and HIF1A $(p<0.05)$, or showed a trend of being upregulated, i.e., $C 3(p=0.06$; Fig. $6 \mathrm{~B})$, confirming the proinflammatory hippocampal response observed at the histological level.

\section{Discussion}

Neonates exposed to intrauterine infection/inflammation have an increased risk of neurological, cognitive and neuropsychiatric disorders later in life (Pinelli \& Zwaigenbaum, 2008; Hagberg et al., 2015; Estes \& McAllister, 2016; Thorell et al., 2020). However, the underlying mechanisms and biomarkers of brain disturbances caused by the many different types and intensities of fetal inflammation have not been elucidated. In the current study, we characterized the proteomic responses of the CSF and brain after a brief period (3 days) of LPS exposure just before preterm birth, modelling infants born prematurely under conditions of maternal CA. We found transient and only moderate changes in CSF protein levels at birth, followed by limited, but significant, hippocampal microgliosis and protein expression changes five days later. Similar to CA, temporary exposure of the amniotic sac in pig fetuses to LPS induced a limited systemic inflammatory response (Nguyen et al., 2018), which potentially resulted in multiple local inflammatory insults via contact with the skin, lung and gastrointestinal tract. Such peripherally administered LPS likely has limited ability to enter the brain, even after BBB disruption (Banks \& Robinson, 2010). In contrast to systemic LPS stimulation, which results in a robust and broad cytokine response in the brain (Schwarz \& Bilbo, 2011), intraamniotic LPS exposure has previously been shown to elicit a limited proinflammatory cytokine response in fetal brain tissues (Brown et al., 2019). Thus, we speculate that the observed changes in the CNS were induced by multiple focal immune responses that indirectly affected the fetal brain via upregulation of the plasma, liver and kidney inflammatory proteins that we described previously (Muk et al., 2020). The absence of dramatic changes in the CSF proteome or 
leukocytes at birth, with limited brain tissue responses five days after birth, confirmed that the LPSinduced CNS inflammatory responses were relatively mild in this model.

Most fetal neuroinflammation experiments have been conducted in rodents and lambs, which generally do not exhibit more than a few hours of postnatal viability after preterm birth. In contrast, preterm pigs can be resuscitated and are viable for days or even weeks with intensive care. This unique model enables the investigation of how prenatal and postnatal factors interact to determine neurological outcomes in preterm neonates (Nguyen et al., 2016; Mudd \& Dilger, 2017; Antonson et al., 2019; Muk et al., 2019; Plomgaard et al., 2019). Moreover, the immune system and anatomical development of the brain in pigs may be more similar to those of human infants (Nguyen et al., 2016; Mudd \& Dilger, 2017). Furthermore, the large litter size of genetically related piglets (18-24 pigs per litter), birth-related clinical complications similar to those of human preterm infants and good survival after initial rearing in incubators make preterm pigs a particularly suitable model for studies of disordered neurodevelopment (Sangild et al., 2013; Andersen et al., 2016; Sun et al., 2018; Brunse et al., 2019).

In this study, the upregulation of the expression of complement system elements, such as C3 and CFB, in the CSF at P1 was correlated with the upregulation of the expression of these proteins in plasma, suggesting the systemic origin of these CSF proteins. However, at a later time point, i.e., P5, we observed the upregulated expression of $C 3$ and other inflammation-associated genes, such as $\angle B P, S 100 A 9$ and HIF1a, in the hippocampus, suggesting that a primary neuroinflammatory response occurred, particularly in the hippocampus, where the activation of microglia was also confirmed at the histological level. Importantly, in the brain, the function of complement cascade products, including complement C3, extends beyond inflammation. Such proteins are partly responsible for shaping the synaptic network in early brain development (Stevens et al., 2007; Schafer et al., 2012), and their expression is upregulated in different pathological settings related to neuroinflammation, demyelination and neurodegeneration (reviewed in (Kettenmann et al., 2013; Druart \& Le Magueresse, 2019). Altered C3 levels were also noted in the CSF of patients with bacterial meningitis (Stahel et al., 1997). In addition, during brain development, C3 is functionally important for migrating neurons (Gorelik et al., 2017) and may inhibit neurogenesis (Moriyama et al., 2011). Interestingly, since the complement system is mechanistically involved in synapse elimination, its activation in the perinatal period was suggested to be linked to psychiatric conditions, such as schizophrenia and autism spectrum disorder (Druart \& Le Magueresse, 2019). Thus, the upregulation of C3 levels in the CSF followed by microglial activation might be a link between neuroinflammation and altered synaptic organization (Kettenmann et al., 2013). The observed increased levels of VIP, a neurotrophic factor and neurotransmitter centrally involved in the control of GABAergic transmission, and upregulated expression of the postsynaptic protein PRICKLE2 in the hippocampus on P5, both of which were previously linked to the pathophysiology of epilepsy and autism-like behavior (Hida et al., 2011; Bayat et al., 2021), further strengthen this association.

Several downregulated CSF proteins, such as UBE2N (Yin et al., 2015), RCN2 (Kirkpatrick et al., 2000), FGFR1, BASP1 and HSPD1 (Heo et al., 2018), were previously shown to be associated with synaptic homeostasis and maturation, and their decreased expression might further highlight the possible 
involvement of brief CA-induced inflammatory conditions in aberrant synaptic remodeling (Mottahedin et al., 2017). In particular, the HSPD1 protein, a constitutive mitochondrial heat shock protein expressed in astrocytes, neurons and other neuronal cells (D'Souza \& Brown, 1998), was recently identified as a longlived protein associated with synapses (Heo et al., 2018), and its downregulated expression may thus reflect the long-lasting synaptic maldevelopment linking CA with childhood and adolescent cognitive dysfunctions (Pinelli \& Zwaigenbaum, 2008; Estes \& McAllister, 2016; Mottahedin et al., 2017). Furthermore, the transient decrease in the abundance of CSF proteins that, among other functions, are involved in neuronal survival, such as ATOX1 (Kelner et al., 2000), HSPD1, FGFR1, and cellular adhesion and angiogenesis, such as Talin1 (Gough \& Goult, 2018), as well as the upregulated expression of the septic biomarker CPN2 (Jiao et al., 2014), which is involved in brain lipid metabolism (Bouyakdan et al., 2015), also indicate disrupted cerebral homeostasis following CA.

In connection with the findings listed above, the observed downregulation of FGFR1 and BASP1 protein expression in the CSF at P1 and the upregulated expression of these genes in the hippocampus at P5 are of particular interest. Both FGFR1 and BASP1 are abundantly expressed in the developing brain and regulate neurite outgrowth and synapse differentiation, hence being centrally implicated in neuronal plasticity (Frey et al., 2000; Klimaschewski \& Claus, 2021). In particular, BASP1 was previously shown to be involved in stimuli-induced synaptic changes (Frey et al., 2000). However, FGFR1, in addition to its canonical function as a cell membrane receptor, can also be translocated to the nucleus, where it controls neuronal growth and differentiation and is suggested to be involved in the pathogenesis of schizophrenia, particularly via its nuclear signaling (reviewed in (Narla et al., 2017)). In addition, FGFR1 can directly interact with CD200 (Pankratova et al., 2016), an immunomodulatory glycoprotein expressed primarily on neurons, and thus modulate neuron-microglia communication (Chamera et al., 2020). We suggest that hippocampal upregulation of the expression of these genes at P5 might be a delayed compensatory reaction of tissues to the IA LPS-induced early decrease in the expression of these proteins in CSF at P1. The observed altered expression of these targets at the protein and gene levels adds further weight to the argument that CA-induced inflammation may affect synaptogenesis/synaptic plasticity a few days after exposure and potentially predispose the appearance of late-onset neuronal dysfunctions.

Microglia are a highly plastic cerebral resident myeloid cell population representing $10-15 \%$ of total brain cells and are key contributors to the neuroinflammatory response after CNS insults and peripheral pathological conditions (Mottahedin et al., 2017). Despite methodological differences across models, exposure to LPS or viral infection was shown to increase microglial activation and/or cell density in rodent (Cai et al., 2000; Girard et al., 2010; O'Loughlin et al., 2017), ovine and porcine models of fetal inflammation, although these models require different intervals and severity of IA exposure (Gavilanes et al., 2009; Schaafsma et al., 2017; Gussenhoven et al., 2018; Antonson et al., 2019). Of note, in our model, reactive microgliosis, reflected by increased Iba $1^{+}$-ir, was observed on P5, particularly in the hippocampus, which is the brain region centrally involved in memory and cognitive processes and previously shown to be highly sensitive to fetal inflammatory challenges (Golan et al., 2005; Matcovitch-Natan et al., 2016). The CA-induced hippocampal neuroinflammatory response in preterm pigs may explain why preterm 
infants exposed to CA have smaller hippocampal volumes (Hatfield et al., 2011), which in turn correlates with poor working memory at later time points (Beauchamp et al., 2008).

In our model, short IA LPS stimulation showed an undistinguishable astroglial response, as indicated by GFAP-ir, in different brain regions and at both early- (P1) and later (P5) postnatal time points. In contrast, in a rat model of feto-maternal inflammation, GFAP expression was transiently increased in the hippocampus and other brain regions (PVWM, prefrontal cortex) of infected pups at P7 (Cai et al., 2000; Yu et al., 2004). We suggest that in pigs, a longer postnatal follow-up analysis is required to detect the potential effect of in utero LPS stimulation on astrocyte activation. The inflammatory threshold (time, duration, and type) required to elicit fetal brain damage in preterm pigs is unknown and remains to be investigated in this model.

In addition to the impact of CA inflammation, we observed significant postnatal developmental changes in GFAP-ir specifically in PVWM, a white matter bundle especially vulnerable to inflammatory agents in premature infants (Rees \& Inder, 2005). Similar to preterm infants, preterm pigs were characterized by an immature microstructure of white matter (Plomgaard et al., 2019). The observed developmental increase in $\mathrm{GFAP}^{+}$-ir in this region is supported by the strong role of astrocytes in ongoing myelination processes (Li et al., 2016), which in pigs peak during the perinatal period in a biphasic manner, i.e., 2 weeks before and 3 weeks after birth (Sweasey et al., 1976). Our results (Fig. 4B) are also consistent with previous observations that white matter-derived astrocytes expressed higher levels of GFAP than astrocytes from the gray matter (Goursaud et al., 2009). Similar to astroglia, we observed significant developmental changes in $\mathrm{Iba} 1^{+}$-ir, albeit in an opposite direction; its level in both the hippocampus and PVWM was significantly decreased from P1 to P5. Consistent with this observation, a decrease in hippocampal microglia number was previously shown in rat pups within the first four postnatal days (Schwarz et al., 2012) and in prenatal pigs (Antonson et al., 2019). The early postnatal decrease in lba $1^{+}$-ir might be indicative of the maturation process of microglial cells, whose phenotype is known to evolve from amoeboid (activated and/or proliferating) to mature ramified shapes in the perinatal period (Bilbo \& Schwarz, 2012).

Overall, our data indicate that a brief period of in utero LPS exposure induces a moderate, yet significant, change in CSF protein levels at birth, coupled with later postnatal histopathological region-dependent alterations in the developing pig brain. The changes in hippocampal gene and protein expression indicate transient neuroinflammation and an adapted synaptic plasticity response. The detected CSF proteins may serve as biomarkers of later structural brain alterations in infants exposed to a relatively short period of inflammation before preterm birth. Such biomarkers may help to identify preterm infants eligible for therapies to improve recovery from these CA-related neurological sequelae. The preterm pig is a suitable model to further define how different times, durations and types of prenatal inflammation may affect the developing immature brain and how early biomarkers in biofluids, such as plasma, CSF or urine, could be important for early diagnosis, preventive treatments and early therapies.

\section{Abbreviations}


ATOX1 Antioxidant protein 1

BASP1 Brain acid soluble protein 1

C3 Complement C3

CA Chorioamnionitis

CFB complement factor B

CLD11 claudin 11

CPN2 Carboxypeptidase $\mathrm{N}$ subunit 2

CSF Cerebrospinal fluid

DEPs Differentially expressed proteins

FGFR1 Fibroblast growth factor receptor 1

GA Gestational age

GFAP Glial fibrillary acidic protein

HIF1A Hypoxia inducible factor 1 subunit alpha

HPRT Hypoxanthine-guanine phosphoribosyltransferase 1

HPX hemopexin

HSPD1 heat shock protein family D (Hsp60) member 1

Iba1 lonized calcium-binding adapter molecule 1

IHC Immunohistochemistry

ITIH1 Inter-alpha-trypsin inhibitor heavy chain 1

LBP Lipopolysaccharide-binding protein

LPS Lipopolysaccharide

MIA3 Melanoma inhibitor protein 3

MINPP1 Multiple inositol polyphosphate phosphatase 1

PLLP Plasmolipin

Page $12 / 26$ 
PRICKLE2 Prickle homolog 2

PVWM Periventricular white matter

qPCR Quantitative real-time PCR

RNA2 Reticulocalbin 2

S100A9 S100 Calcium Binding Protein A9

SEM Standard error of the mean

UBE2N Ubiquitin conjugating enzyme E2 N

VIP Vasoactive intestinal peptide

\section{Declarations}

\section{Ethics approval and consent to participate}

The animal experimental protocol was approved by the Danish Animal Experiments Inspectorate (license number, 2014-15-0201-00418), which is in accordance with the guidelines from Directive 2010/63/EU of the European Parliament.

\section{Consent for publication}

Not applicable.

\section{Availability of data and materials}

The proteomics datasets generated during the current study are available in the PRIDE repository (link to data set will be provided).

\section{Competing interests}

The authors declare no conflict of interest.

\section{Funding}

The Danish National Mass Spectrometry Platform for Functional Proteomics (PRO-MS; grant no. 507200007B), the Obel Family Foundation and the Svend Andersen Foundation are acknowledged for grants to the analytical platform, which enabled parts of this study.

\section{Authors' contributions}


TM and SP conceived the study. TM, AS, and P-PJ analyzed the proteomic data. OD performed histological tissue analyses. TM performed qPCR. TM and SP analyzed and interpreted the data, and prepared the manuscript. AB, TT and PTS conceived and performed the animal study and critically revised the manuscript. All authors read and approved the final version.

\section{Acknowledgements}

The authors thank Jane Poulsen and Duc Ninh Nguyen for help with animal experiments.

\section{References}

1. Adams-Chapman I, Stoll BJ. Neonatal infection and long-term neurodevelopmental outcome in the preterm infant. Curr Opin Infect Dis. 2006;19:290-7.

2. Anblagan D, Pataky R, Evans MJ, Telford EJ, Serag A, Sparrow S, Piyasena C, Semple SI, Wilkinson AG, Bastin ME, Boardman JP. Association between preterm brain injury and exposure to chorioamnionitis during fetal life. Sci Rep. 2016;6:37932.

3. Andersen AD, Cilieborg MS, Lauridsen C, Morkbak AL, Sangild PT. Supplementation with Lactobacillus paracasei or Pediococcus pentosaceus does not prevent diarrhoea in neonatal pigs infected with Escherichia coli F18. Br J Nutr. 2017;118:109-20.

4. Andersen AD, Nguyen DN, Langhorn L, Renes IB, van Elburg RM, Hartog A, Tims S, van de Looij Y, Sangild PT, Thymann T. Synbiotics Combined with Glutamine Stimulate Brain Development and the Immune System in Preterm Pigs. J Nutr. 2019;149:36-45.

5. Andersen AD, Sangild PT, Munch SL, van der Beek EM, Renes IB, Ginneken C, Greisen GO, Thymann T. Delayed growth, motor function and learning in preterm pigs during early postnatal life. Am J Physiol Regul Integr Comp Physiol. 2016;310:R481-92.

6. Antonson AM, Lawson MA, Caputo MP, Matt SM, Leyshon BJ, Johnson RW. Maternal viral infection causes global alterations in porcine fetal microglia. Proc Natl Acad Sci U S A. 2019;116:20190-200.

7. Back SA, Rosenberg PA. Pathophysiology of glia in perinatal white matter injury. Glia. 2014;62:1790815.

8. Banks WA, Robinson SM. Minimal penetration of lipopolysaccharide across the murine blood-brain barrier. Brain Behav Immun. 2010;24:102-9.

9. Bayat A, lqbal S, Borredy K, Amiel J, Zweier C, Barcia G, Kraus C, Weyhreter H, Bassuk AG, Chopra M, Rubboli G, Moller RS. (2021) PRICKLE2 revisited-further evidence implicating PRICKLE2 in neurodevelopmental disorders. Eur J Hum Genet.

10. Beauchamp MH, Thompson DK, Howard K, Doyle LW, Egan GF, Inder TE, Anderson PJ. Preterm infant hippocampal volumes correlate with later working memory deficits. Brain. 2008;131:2986-94.

11. Begcevic I, Brinc D, Drabovich AP, Batruch I, Diamandis EP. Identification of brain-enriched proteins in the cerebrospinal fluid proteome by LC-MS/MS profiling and mining of the Human Protein Atlas. Clin Proteomics. 2016;13:11. 
12. Berger ST, Ahmed S, Muntel J, Cuevas Polo N, Bachur R, Kentsis A, Steen J, Steen H. MStern BlottingHigh Throughput Polyvinylidene Fluoride (PVDF) Membrane-Based Proteomic Sample Preparation for 96-Well Plates. Mol Cell Proteomics. 2015;14:2814-23.

13. Bergstrom A, Kaalund SS, Skovgaard K, Andersen AD, Pakkenberg B, Rosenorn A, van Elburg RM, Thymann T, Greisen GO, Sangild PT. (2016) Limited effects of preterm birth and the first enteral nutrition on cerebellum morphology and gene expression in piglets. Physiol Rep, 4.

14. Bilbo SD, Schwarz JM. The immune system and developmental programming of brain and behavior. Front Neuroendocrinol. 2012;33:267-86.

15. Bouyakdan K, Taib B, Budry L, Zhao S, Rodaros D, Neess D, Mandrup S, Faergeman NJ, Alquier T. A novel role for central ACBP/DBI as a regulator of long-chain fatty acid metabolism in astrocytes. $J$ Neurochem. 2015;133:253-65.

16. Brown AG, Maubert ME, Anton L, Heiser LM, Elovitz MA. The tracking of lipopolysaccharide through the feto-maternal compartment and the involvement of maternal TLR4 in inflammation-induced fetal brain injury. Am J Reprod Immunol. 2019;82:e13189.

17. Brunse A, Worsoe P, Pors SE, Skovgaard K, Sangild PT. Oral Supplementation With Bovine Colostrum Prevents Septic Shock and Brain Barrier Disruption During Bloodstream Infection in Preterm Newborn Pigs. Shock. 2019;51:337-47.

18. Burd I, Balakrishnan B, Kannan S. Models of fetal brain injury, intrauterine inflammation, and preterm birth. Am J Reprod Immunol. 2012;67:287-94.

19. Cai Z, Pan ZL, Pang Y, Evans OB, Rhodes PG. Cytokine induction in fetal rat brains and brain injury in neonatal rats after maternal lipopolysaccharide administration. Pediatr Res. 2000;47:64-72.

20. Chamera K, Trojan E, Szuster-Gluszczak M, Basta-Kaim A. The Potential Role of Dysfunctions in Neuron-Microglia Communication in the Pathogenesis of Brain Disorders. Curr Neuropharmacol. 2020;18:408-30.

21. D'Souza SM, Brown IR. Constitutive expression of heat shock proteins Hsp90, Hsc70, Hsp70 and Hsp60 in neural and non-neural tissues of the rat during postnatal development. Cell Stress Chaperones. 1998;3:188-99.

22. Druart M, Le Magueresse C. Emerging Roles of Complement in Psychiatric Disorders. Front Psychiatry. 2019;10:573.

23. Estes ML, McAllister AK. Maternal immune activation: Implications for neuropsychiatric disorders. Science. 2016;353:772-7.

24. Felix B, Leger ME, Albe-Fessard D, Marcilloux JC, Rampin O, Laplace JP. Stereotaxic atlas of the pig brain. Brain Res Bull. 1999;49:1-137.

25. Frey D, Laux T, Xu L, Schneider C, Caroni P. Shared and unique roles of CAP23 and GAP43 in actin regulation, neurite outgrowth, and anatomical plasticity. J Cell Biol. 2000;149:1443-54.

26. Gavilanes AW, Strackx E, Kramer BW, Gantert M, Van den Hove D, Steinbusch H, Garnier Y, Cornips E, Steinbusch H, Zimmermann L, Vles J. Chorioamnionitis induced by intraamniotic lipopolysaccharide 
resulted in an interval-dependent increase in central nervous system injury in the fetal sheep. Am J Obstet Gynecol. 2009;200:437 e431-8.

27. Girard S, Tremblay L, Lepage M, Sebire G. IL-1 receptor antagonist protects against placental and neurodevelopmental defects induced by maternal inflammation. J Immunol. 2010;184:3997-4005.

28. Golan HM, Lev V, Hallak M, Sorokin Y, Huleihel M. Specific neurodevelopmental damage in mice offspring following maternal inflammation during pregnancy. Neuropharmacology. 2005;48:903-17.

29. Gorelik A, Sapir T, Haffner-Krausz R, Olender T, Woodruff TM, Reiner O. Developmental activities of the complement pathway in migrating neurons. Nat Commun. 2017;8:15096.

30. Gough RE, Goult BT. The tale of two talins - two isoforms to fine-tune integrin signalling. FEBS Lett. 2018;592:2108-25.

31. Goursaud S, Kozlova EN, Maloteaux JM, Hermans E. Cultured astrocytes derived from corpus callosum or cortical grey matter show distinct glutamate handling properties. J Neurochem. 2009;108:1442-52.

32. Greenwood S, Swetloff A, Wade AM, Terasaki T, Ferretti P. Fgf2 is expressed in human and murine embryonic choroid plexus and affects choroid plexus epithelial cell behaviour. Cerebrospinal Fluid Res. 2008;5:20.

33. Gussenhoven R, Westerlaken RJJ, Ophelders D, Jobe AH, Kemp MW, Kallapur SG, Zimmermann LJ, Sangild PT, Pankratova S, Gressens P, Kramer BW, Fleiss B, Wolfs T. Chorioamnionitis, neuroinflammation, and injury: timing is key in the preterm ovine fetus. $\mathrm{J}$ Neuroinflammation. 2018;15:113.

34. Hagberg H, Mallard C, Ferriero DM, Vannucci SJ, Levison SW, Vexler ZS, Gressens P. The role of inflammation in perinatal brain injury. Nat Rev Neurol. 2015;11:192-208.

35. Hatfield T, Wing DA, Buss C, Head K, Muftuler LT, Davis EP. Magnetic resonance imaging demonstrates long-term changes in brain structure in children born preterm and exposed to chorioamnionitis. Am J Obstet Gynecol. 2011;205:384 e381-8.

36. Heo S, Diering GH, Na CH, Nirujogi RS, Bachman JL, Pandey A, Huganir RL. Identification of longlived synaptic proteins by proteomic analysis of synaptosome protein turnover. Proc Natl Acad Sci U S A. 2018;115:E3827-36.

37. Hida Y, Fukaya M, Hagiwara A, Deguchi-Tawarada M, Yoshioka T, Kitajima I, Inoue E, Watanabe M, Ohtsuka T. Prickle2 is localized in the postsynaptic density and interacts with PSD-95 and NMDA receptors in the brain. J Biochem. 2011;149:693-700.

38. Holme Nielsen C, Bladt Brandt A, Thymann T, Obelitz-Ryom K, Jiang P, Vanden Hole C, van Ginneken C, Pankratova S, Sangild PT. Rapid Postnatal Adaptation of Neurodevelopment in Pigs Born Late Preterm. Dev Neurosci. 2018;40:586-600.

39. Jain VG, Willis KA, Jobe A, Ambalavanan N. (2021) Chorioamnionitis and neonatal outcomes. Pediatr Res.

40. Jiao J, Gao M, Zhang H, Wang N, Xiao Z, Liu K, Yang M, Wang K, Xiao X. Identification of potential biomarkers by serum proteomics analysis in rats with sepsis. Shock. 2014;42:75-81. 
41. Kaiser K, Bryja V. (2020) Choroid Plexus: The Orchestrator of Long-Range Signalling Within the CNS. Int J Mol Sci, 21.

42. Kelner GS, Lee M, Clark ME, Maciejewski D, McGrath D, Rabizadeh S, Lyons T, Bredesen D, Jenner P, Maki RA. The copper transport protein Atox1 promotes neuronal survival. J Biol Chem. 2000;275:580-4.

43. Kettenmann H, Kirchhoff F, Verkhratsky A. Microglia: new roles for the synaptic stripper. Neuron. 2013;77:10-8.

44. Kirkpatrick LL, Matzuk MM, Dodds DC, Perin MS. Biochemical interactions of the neuronal pentraxins. Neuronal pentraxin (NP) receptor binds to taipoxin and taipoxin-associated calciumbinding protein 49 via NP1 and NP2. J Biol Chem. 2000;275:17786-92.

45. Klimaschewski L, Claus P. (2021) Fibroblast Growth Factor Signalling in the Diseased Nervous System. Mol Neurobiol.

46. Lehtinen MK, Zappaterra MW, Chen X, Yang YJ, Hill AD, Lun M, Maynard T, Gonzalez D, Kim S, Ye P, D'Ercole AJ, Wong ET, LaMantia AS, Walsh CA. The cerebrospinal fluid provides a proliferative niche for neural progenitor cells. Neuron. 2011;69:893-905.

47. Li J, Zhang L, Chu Y, Namaka M, Deng B, Kong J, Bi X. Astrocytes in Oligodendrocyte Lineage Development and White Matter Pathology. Front Cell Neurosci. 2016;10:119.

48. Lun MP, Monuki ES, Lehtinen MK. Development and functions of the choroid plexus-cerebrospinal fluid system. Nat Rev Neurosci. 2015;16:445-57.

49. Matcovitch-Natan O, Winter DR, Giladi A, Vargas Aguilar S, Spinrad A, Sarrazin S, Ben-Yehuda H, David E, Zelada Gonzalez F, Perrin P, Keren-Shaul H, Gury M, Lara-Astaiso D, Thaiss CA, Cohen M, Bahar Halpern K, Baruch K, Deczkowska A, Lorenzo-Vivas E, Itzkovitz S, Elinav E, Sieweke MH, Schwartz M, Amit I. Microglia development follows a stepwise program to regulate brain homeostasis. Science. 2016;353:aad8670.

50. Meyer U, Nyffeler M, Engler A, Urwyler A, Schedlowski M, Knuesel I, Yee BK, Feldon J. The time of prenatal immune challenge determines the specificity of inflammation-mediated brain and behavioral pathology. J Neurosci. 2006;26:4752-62.

51. Moriyama M, Fukuhara T, Britschgi M, He Y, Narasimhan R, Villeda S, Molina H, Huber BT, Holers $M$, Wyss-Coray T. Complement receptor 2 is expressed in neural progenitor cells and regulates adult hippocampal neurogenesis. J Neurosci. 2011;31:3981-9.

52. Mottahedin A, Ardalan M, Chumak T, Riebe I, Ek J, Mallard C. Effect of Neuroinflammation on Synaptic Organization and Function in the Developing Brain: Implications for Neurodevelopmental and Neurodegenerative Disorders. Front Cell Neurosci. 2017;11:190.

53. Mudd AT, Dilger RN. Early-Life Nutrition and Neurodevelopment: Use of the Piglet as a Translational Model. Adv Nutr. 2017;8:92-104.

54. Muk T, Jiang PP, Stensballe A, Skovgaard K, Sangild PT, Nguyen DN. Prenatal Endotoxin Exposure Induces Fetal and Neonatal Renal Inflammation via Innate and Th1 Immune Activation in Preterm Pigs. Front Immunol. 2020;11:565484. 
55. Muk T, Stensballe A, Pankratova S, Nguyen DN, Brunse A, Sangild PT, Jiang PP. Rapid Proteome Changes in Plasma and Cerebrospinal Fluid Following Bacterial Infection in Preterm Newborn Pigs. Front Immunol. 2019;10:2651.

56. Narla ST, Lee YW, Benson CA, Sarder P, Brennand KJ, Stachowiak EK, Stachowiak MK. Common developmental genome deprogramming in schizophrenia - Role of Integrative Nuclear FGFR1 Signaling (INFS). Schizophr Res. 2017;185:17-32.

57. Nasef N, Shabaan AE, Schurr P, laboni D, Choudhury J, Church P, Dunn MS. Effect of clinical and histological chorioamnionitis on the outcome of preterm infants. Am J Perinatol. 2013;30:59-68.

58. Nguyen DN, Jiang P, Frokiaer H, Heegaard PM, Thymann T, Sangild PT. Delayed development of systemic immunity in preterm pigs as a model for preterm infants. Sci Rep. 2016;6:36816.

59. Nguyen DN, Thymann T, Goericke-Pesch SK, Ren S, Wei W, Skovgaard K, Damborg P, Brunse A, van Gorp C, Kramer BW, Wolfs TG, Sangild PT. Prenatal Intra-Amniotic Endotoxin Induces Fetal Gut and Lung Immune Responses and Postnatal Systemic Inflammation in Preterm Pigs. Am J Pathol. 2018;188:2629-43.

60. O'Loughlin E, Pakan JMP, Yilmazer-Hanke D, McDermott KW. Acute in utero exposure to lipopolysaccharide induces inflammation in the pre-and postnatal brain and alters the glial cytoarchitecture in the developing amygdala. J Neuroinflammation. 2017;14:212.

61. Obelitz-Ryom K, Bering SB, Overgaard SH, Eskildsen SF, Ringgaard S, Olesen JL, Skovgaard K, Pankratova S, Wang B, Brunse A, Heckmann AB, Rydal MP, Sangild PT, Thymann T. (2019) Bovine Milk Oligosaccharides with Sialyllactose Improves Cognition in Preterm Pigs. Nutrients, 11.

62. Obelitz-Ryom K, Rendboe AK, Nguyen DN, Rudloff S, Brandt AB, Nielsen DS, Heckmann AB, Chichlowski M, Sangild PT, Thymann T, Bering SB. (2018) Bovine Milk Oligosaccharides with Sialyllactose for Preterm Piglets. Nutrients, 10.

63. Pankratova S, Bjornsdottir H, Christensen C, Zhang L, Li S, Dmytriyeva O, Bock E, Berezin V. Immunomodulator CD200 Promotes Neurotrophic Activity by Interacting with and Activating the Fibroblast Growth Factor Receptor. Mol Neurobiol. 2016;53:584-94.

64. Penn AA, Gressens P, Fleiss B, Back SA, Gallo V. Controversies in preterm brain injury. Neurobiol Dis. 2016;92:90-101.

65. Pinelli J, Zwaigenbaum L. Chorioamnionitis, gestational age, male sex, birth weight, and illness severity predicted positive autism screening scores in very-low-birth-weight preterm infants. Evid Based Nurs. 2008;11:122.

66. Plomgaard AM, Andersen AD, Petersen TH, van de Looij Y, Thymann T, Sangild PT, Thomsen C, Sizonenko SV, Greisen G. Structural brain maturation differs between preterm and term piglets, whereas brain activity does not. Acta Paediatr. 2019;108:637-44.

67. Rasmussen MK, Mestre H, Nedergaard M. The glymphatic pathway in neurological disorders. Lancet Neurol. 2018;17:1016-24.

68. Rees S, Inder T. Fetal and neonatal origins of altered brain development. Early Hum Dev. 2005;81:753-61. 
69. Reiber H. Dynamics of brain-derived proteins in cerebrospinal fluid. Clin Chim Acta. 2001;310:17386.

70. Sangild PT, Thymann T, Schmidt M, Stoll B, Burrin DG, Buddington RK. Invited review: the preterm pig as a model in pediatric gastroenterology. J Anim Sci. 2013;91:4713-29.

71. Sawamoto K, Wichterle H, Gonzalez-Perez O, Cholfin JA, Yamada M, Spassky N, Murcia NS, GarciaVerdugo JM, Marin O, Rubenstein JL, Tessier-Lavigne M, Okano H, Alvarez-Buylla A. New neurons follow the flow of cerebrospinal fluid in the adult brain. Science. 2006;311:629-32.

72. Schafer DP, Lehrman EK, Kautzman AG, Koyama R, Mardinly AR, Yamasaki R, Ransohoff RM, Greenberg ME, Barres BA, Stevens B. Microglia sculpt postnatal neural circuits in an activity and complement-dependent manner. Neuron. 2012;74:691-705.

73. Schwarz JM, Bilbo SD. LPS elicits a much larger and broader inflammatory response than Escherichia coli infection within the hippocampus of neonatal rats. Neurosci Lett. 2011;497:110-5.

74. Schwarz JM, Sholar PW, Bilbo SD. Sex differences in microglial colonization of the developing rat brain. J Neurochem. 2012;120:948-63.

75. Schaafsma W, Basterra LB, Jacobs S, Brouwer N, Meerlo P, Schaafsma A, Boddeke E, Eggen BJL. Maternal inflammation induces immune activation of fetal microglia and leads to disrupted microglia immune responses, behavior, and learning performance in adulthood. Neurobiol Dis. 2017;106:291-300.

76. Srinivasan L, Shah SS, Padula MA, Abbasi S, McGowan KL, Harris MC. Cerebrospinal fluid reference ranges in term and preterm infants in the neonatal intensive care unit. J Pediatr. 2012;161:729-34.

77. Stahel PF, Nadal D, Pfister HW, Paradisis PM, Barnum SR. Complement C3 and factor B cerebrospinal fluid concentrations in bacterial and aseptic meningitis. Lancet. 1997;349:1886-7.

78. Stevens B, Allen NJ, Vazquez LE, Howell GR, Christopherson KS, Nouri N, Micheva KD, Mehalow AK, Huberman AD, Stafford B, Sher A, Litke AM, Lambris JD, Smith SJ, John SW, Barres BA. The classical complement cascade mediates CNS synapse elimination. Cell. 2007;131:1164-78.

79. Strackx E, Jellema RK, Rieke R, Gussenhoven R, Vles JS, Kramer BW, Gavilanes AW. (2015) IntraAmniotic LPS Induced Region-Specific Changes in Presynaptic Bouton Densities in the Ovine Fetal Brain. Biomed Res Int, 2015, 276029.

80. Sun J, Pan X, Christiansen LI, Yuan XL, Skovgaard K, Chatterton DEW, Kaalund SS, Gao F, Sangild PT, Pankratova S. Necrotizing enterocolitis is associated with acute brain responses in preterm pigs. $J$ Neuroinflammation. 2018;15:180.

81. Sweasey D, Patterson DS, Glancy EM. Biphasic myelination and the fatty acid composition of cerebrosides and cholesterol esters in the developing central nervous system of the domestic pig. $\mathrm{J}$ Neurochem. 1976;27:375-80.

82. Thorell A, Hallingstrom M, Hagberg H, Fyhr IM, Tsiartas P, Olsson I, Chaplin JE, Mallard C, Jacobsson B, Savman K. Microbial invasion of the amniotic cavity is associated with impaired cognitive and motor function at school age in preterm children. Pediatr Res. 2020;87:924-31. 
83. Urakubo A, Jarskog LF, Lieberman JA, Gilmore JH. Prenatal exposure to maternal infection alters cytokine expression in the placenta, amniotic fluid, and fetal brain. Schizophr Res. 2001;47:27-36.

84. Versland LB, Sommerfelt K, Elgen I. Maternal signs of chorioamnionitis: persistent cognitive impairment in low-birthweight children. Acta Paediatr. 2006;95:231-5.

85. Yin P, Tu Z, Yin A, Zhao T, Yan S, Guo X, Chang R, Zhang L, Hong Y, Huang X, Zhou J, Wang Y, Li S, Li $X J$. Aged monkey brains reveal the role of ubiquitin-conjugating enzyme UBE2N in the synaptosomal accumulation of mutant huntingtin. Hum Mol Genet. 2015;24:1350-62.

86. Yu HM, Yuan TM, Gu WZ, Li JP. Expression of glial fibrillary acidic protein in developing rat brain after intrauterine infection. Neuropathology. 2004;24:136-43.

87. Zappaterra MD, Lisgo SN, Lindsay S, Gygi SP, Walsh CA, Ballif BA. A comparative proteomic analysis of human and rat embryonic cerebrospinal fluid. J Proteome Res. 2007;6:3537-48.

88. Ziegler AN, Levison SW, Wood TL. Insulin and IGF receptor signalling in neural-stem-cell homeostasis. Nat Rev Endocrinol. 2015;11:161-70.

\section{Figures}


A

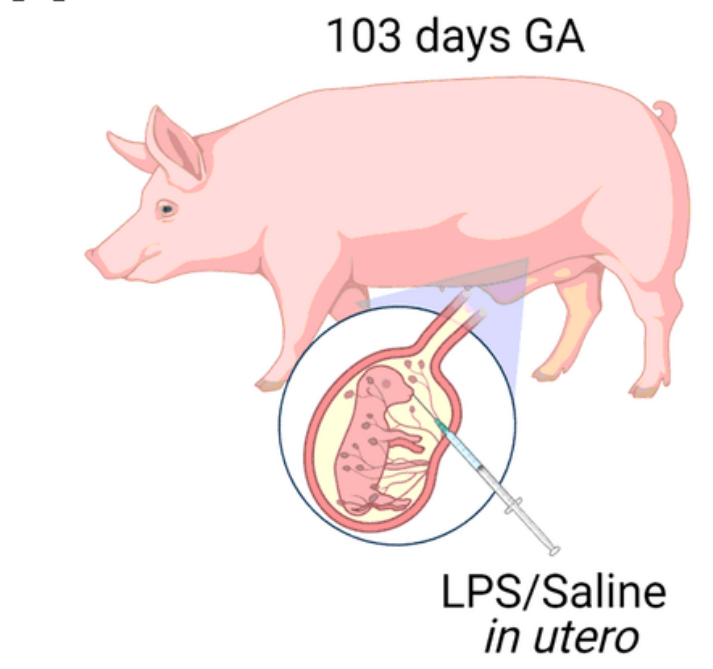

B

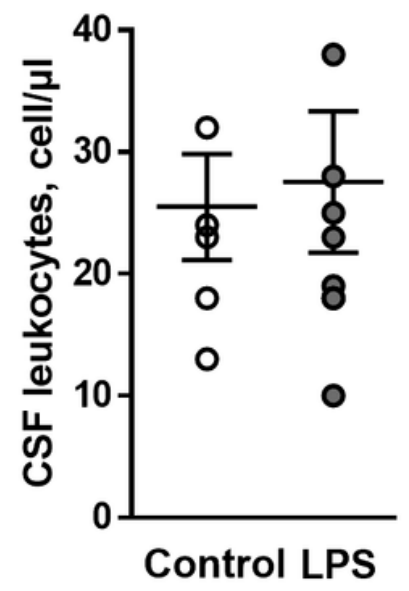

C-section

106 days $\mathrm{GA}$

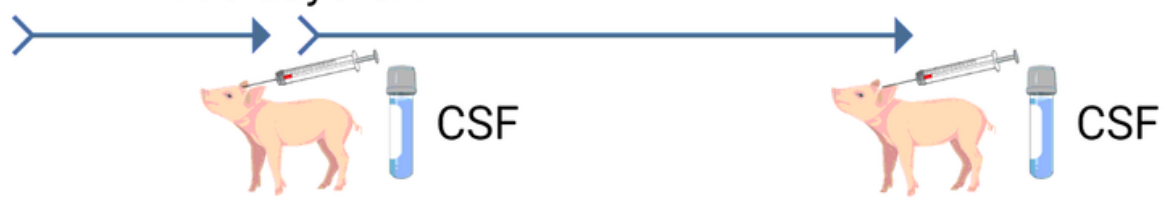

Day 1

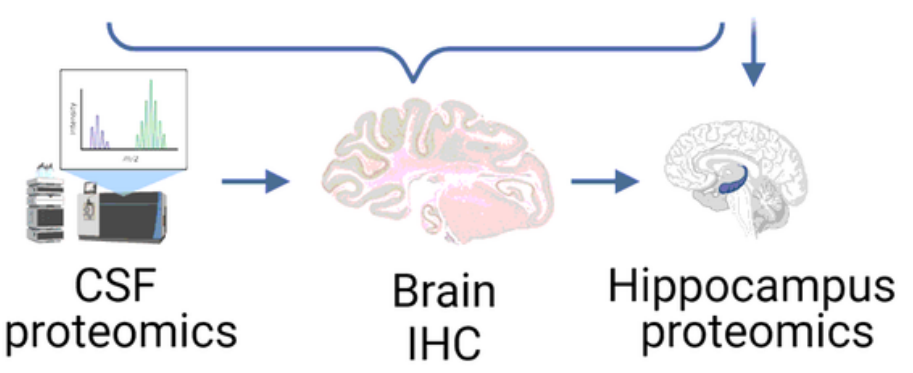

Liver

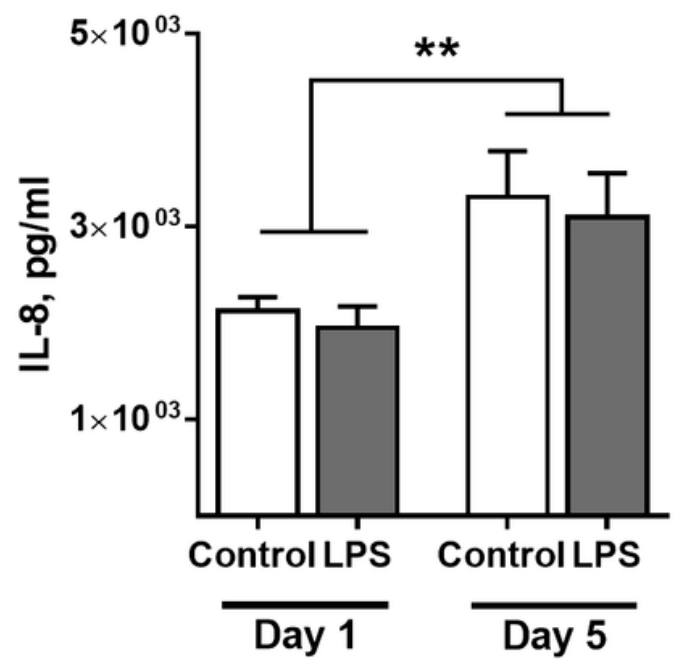

Spleen

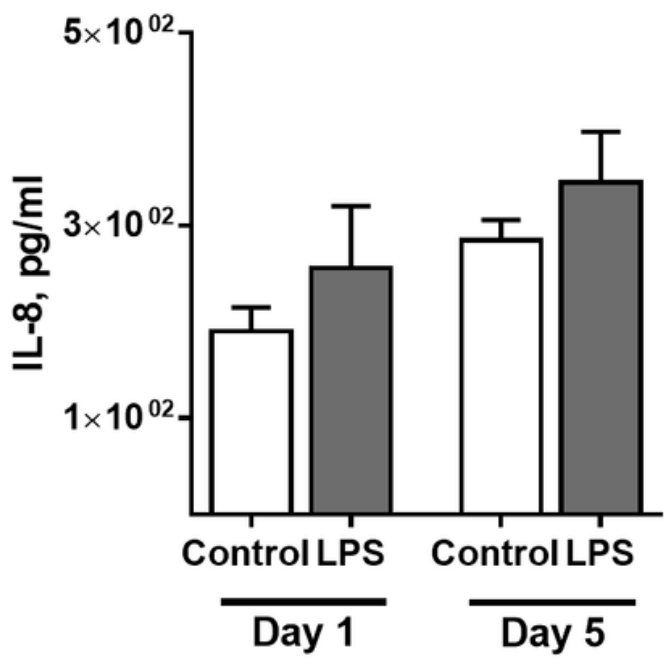

Figure 1

The outline of the experimental setup. Chorioamnionitis (CA) was induced by intra-amniotic infusion of LPS in pregnant sows at 103 days of gestational age (GA). Preterm piglets were born by cesarean section at 106 days GA, and cerebrospinal fluid (CSF) and tissue samples were collected either on Day 1 or Day 5 for proteomics, ELISA, qPCR and immunohistochemistry (IHC) analyses. (B) Leucocyte counts in the CSF of vehicle (Control) and LPS-exposed pigs measured at Day 1. (C) Expression of the proinflammatory cytokine IL-8 in the liver and spleen at P1 and P5. The values are presented as mean $\pm S E M$, ${ }^{\star *} p<0.01$. 
A

Plasma DEPs

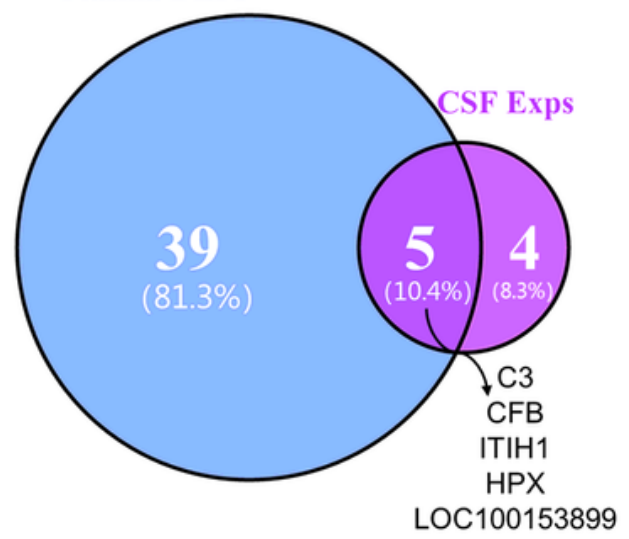

Hemopexin

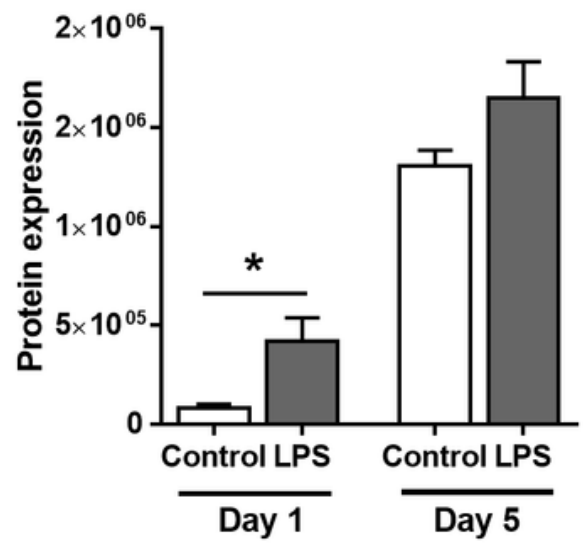

C3

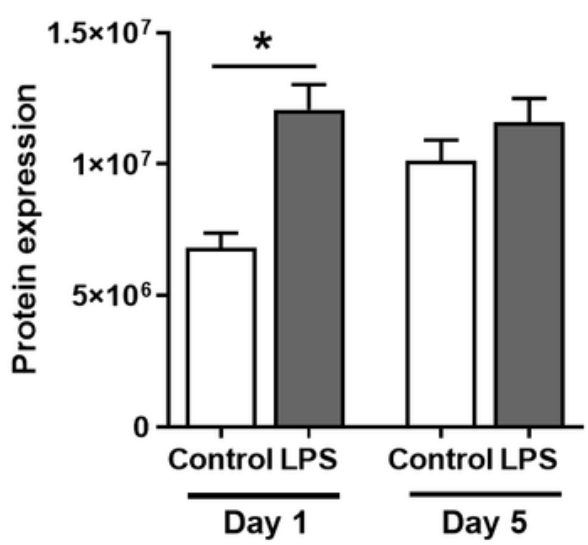

Plasminogen

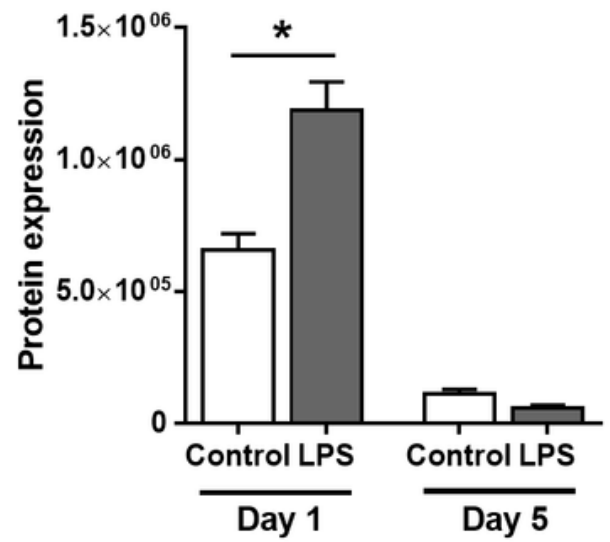

CFB

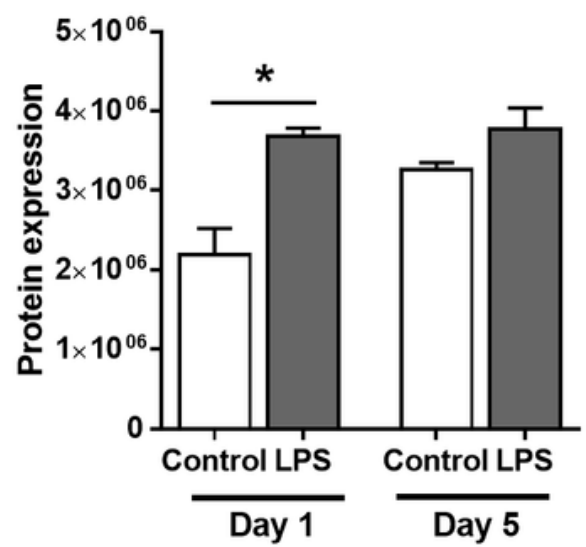

ITIH1

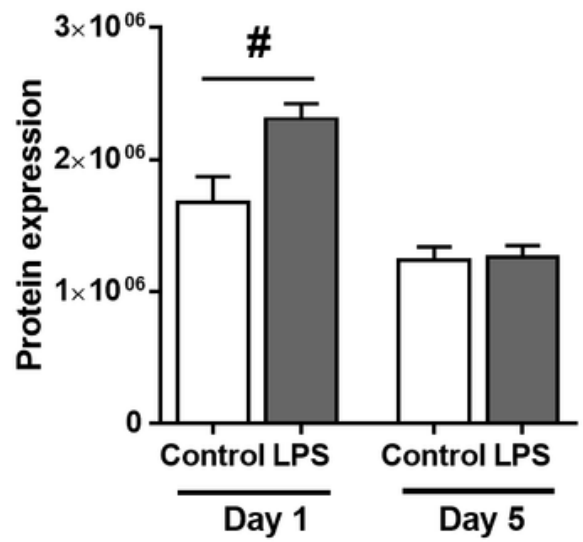

FGFR1

BASP1
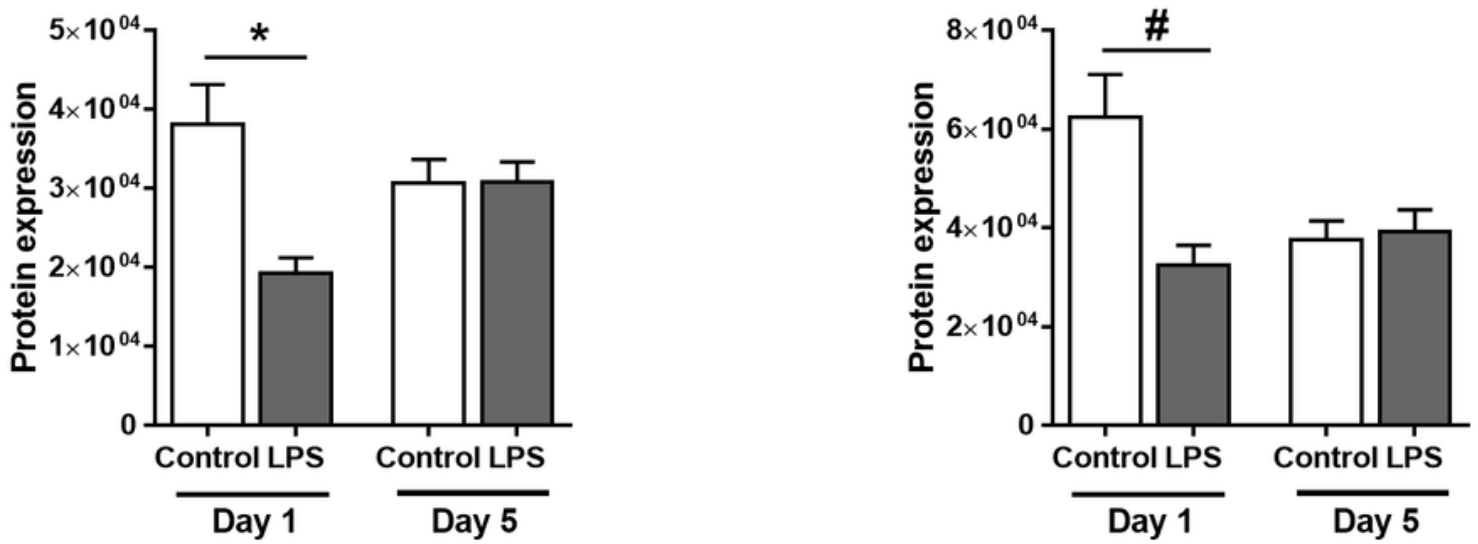

Figure 2

Prenatal intra-amniotic LPS exposure marginally alters the CSF protein profile at birth. Effect DEPS selected by the criterion that one protein was detected in at least $80 \%$ of all the samples from each group. (A) Venn diagram illustrating the overlapping DEPs between plasma and CSF. (B) The expression of the CSF DEPs C3, CFB, hemopexin, plasminogen and ITIH1, which was upregulated by fetal LPS exposure, on P1. (C) The expression of the CSF DEPs FGFR1 and BASP1, which was downregulated by fetal LPS 
exposure, on P1. The data are presented as the mean \pm SEM. *, $\mathrm{q} \leq 0.05$; \#, $\mathrm{q} \leq 0.01$. C3, CFB, ITIH1, FGFR1 and BASP1, Complement C3, Complement factor B, Inter-alpha-trypsin inhibitor heavy chain H1, Fibroblast growth factor receptor 1, Brain acid soluble protein 1.

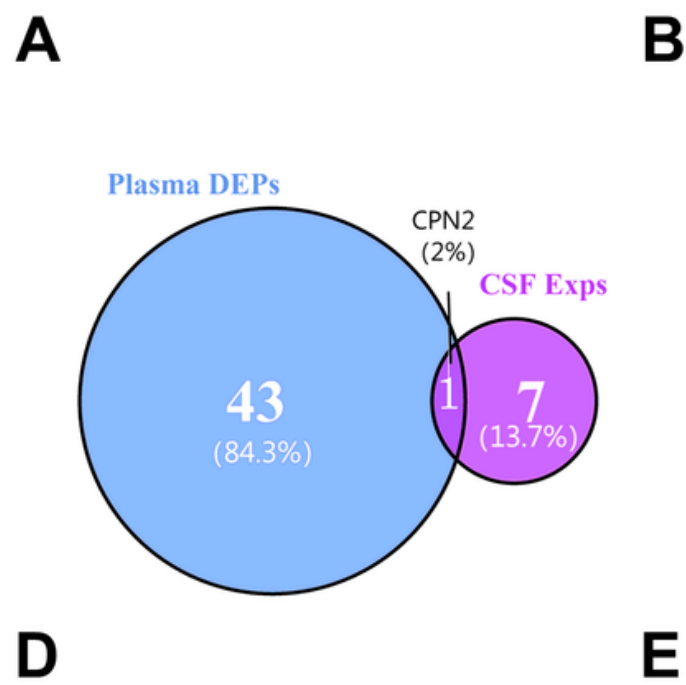

Aminoacylase 1

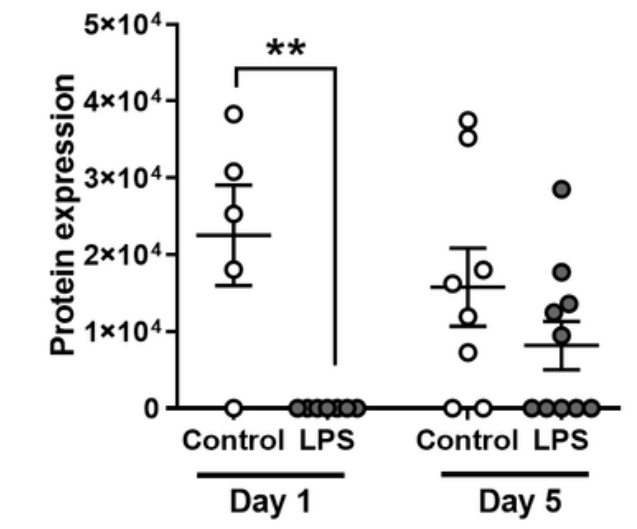

G

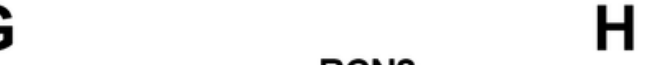

RCN2

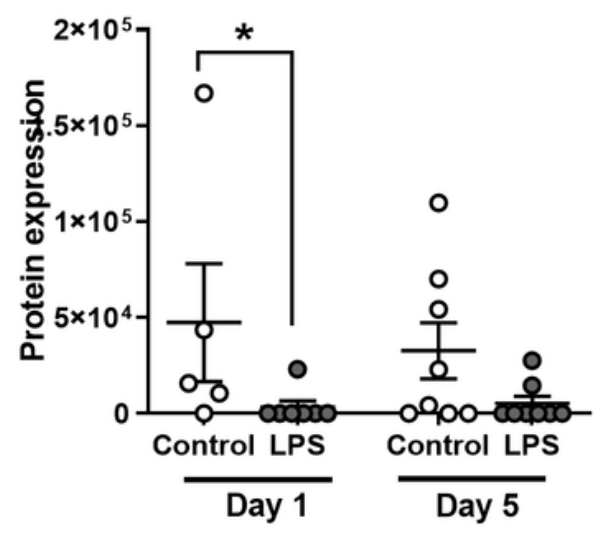

Talin 1

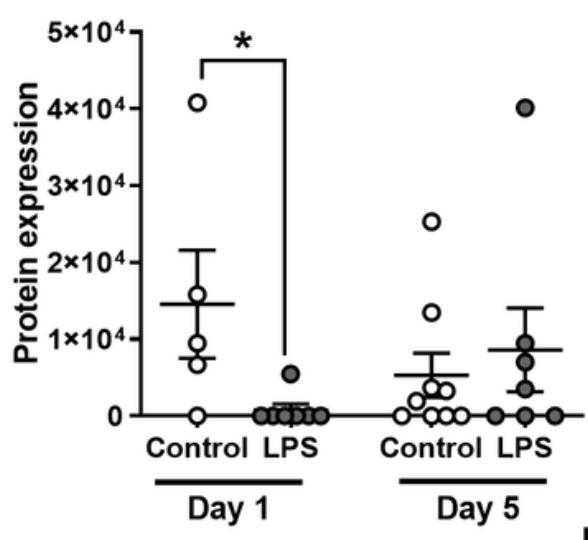

HSPD1

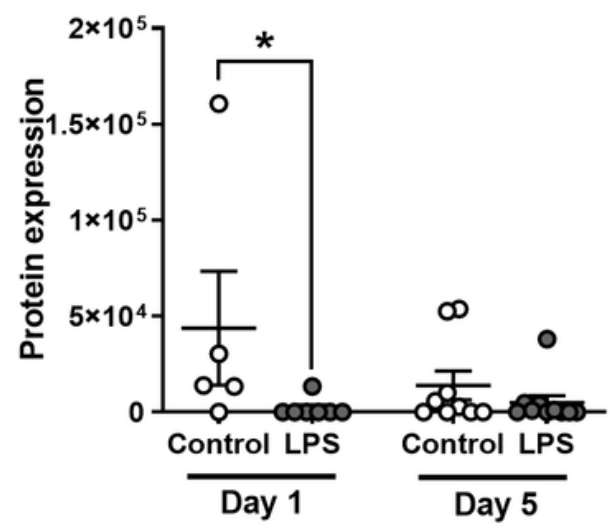

VIP

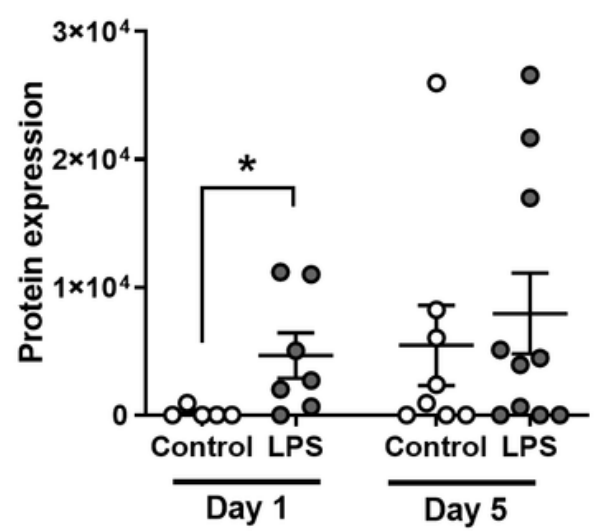

ATOX1

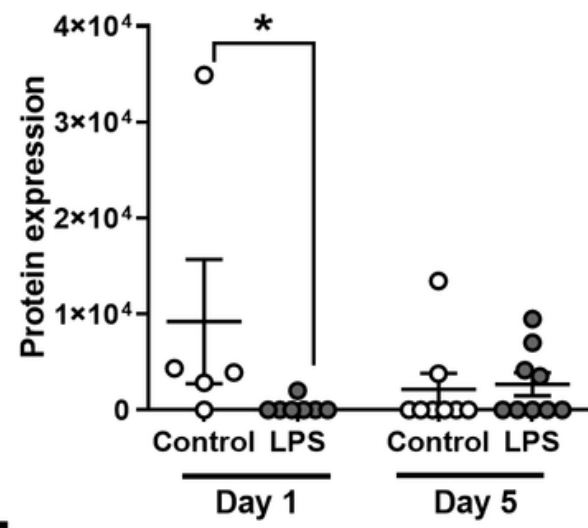

UBE2N

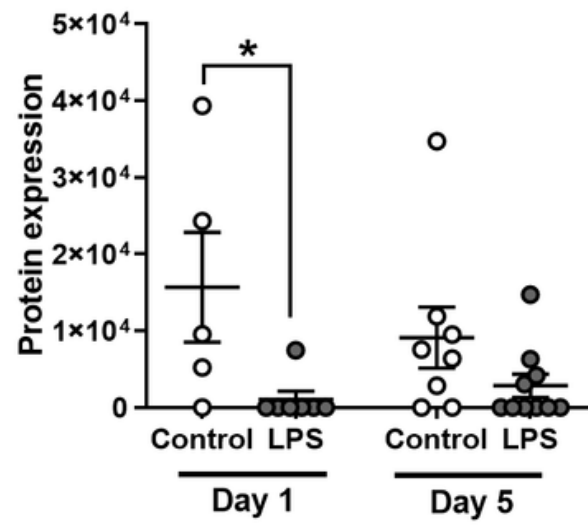

CPN2

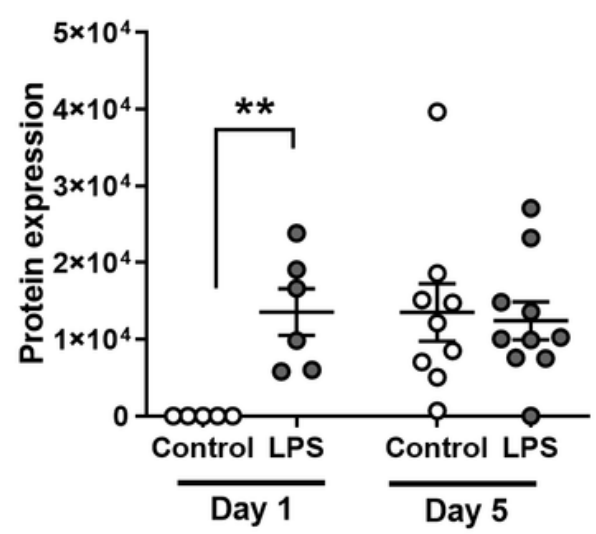

Figure 3

Prenatal intra-amniotic LPS exposure marginally alters the CSF protein profile at birth. Exposure DEPS selected by the criterion that one protein is detected in at least $80 \%$ of all the samples from one group and 
less than $20 \%$ of all the samples from the other group. (A) Venn diagram illustrating the overlap between plasma effect DEPs and CSF exposure DEPs. (B-G) The expression of the CSF exposure DEPs Talin1, ATOX1, Aminoacylase, HSPD1, UBE2N and RNA2, which were detected mostly in the control group after fetal LPS exposure on P1. (H-I) The expression of the CSF exposure DEPs VIP and CPN2, which were detected mostly in the LPS group, but not in the control group, on P1. The data are presented as the mean \pm SEM. ${ }^{*}, \mathrm{q} \leq 0.05 ; * \star, \mathrm{q} \leq 0.01$. ATOX1: Antioxidant protein 1; HSPD1: heat shock protein family $\mathrm{D}$ (Hsp60) member 1; UBE2N: ubiquitin conjugating enzyme E2 N; RNA2: reticulocalbin 2; VIP: vasoactive intestinal peptide; CPN2: carboxypeptidase $\mathrm{N}$ subunit 2.

A

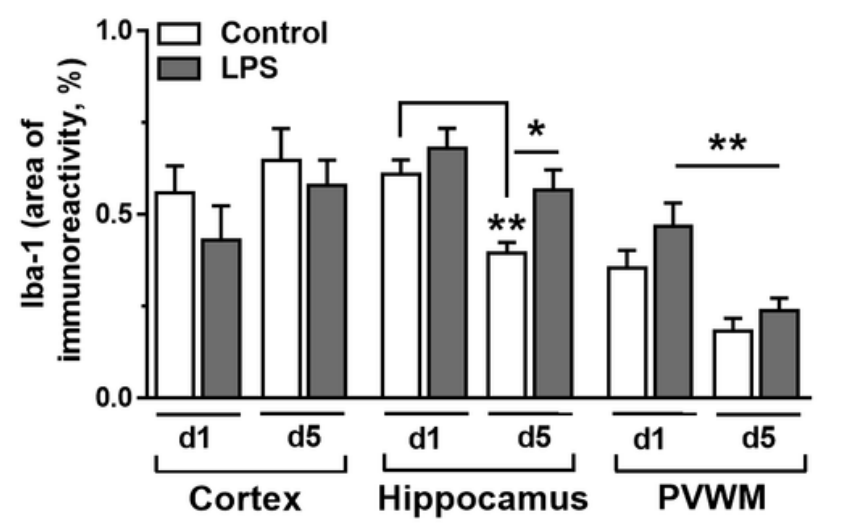

B

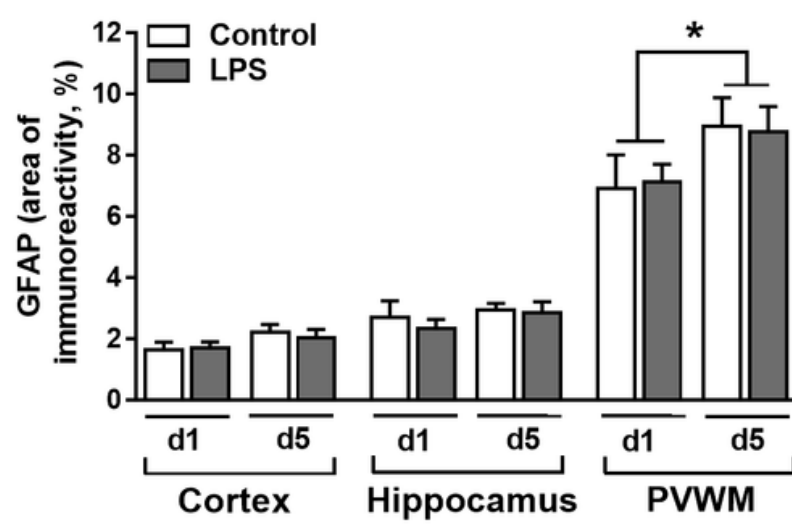

\section{Hippocampus}

Control
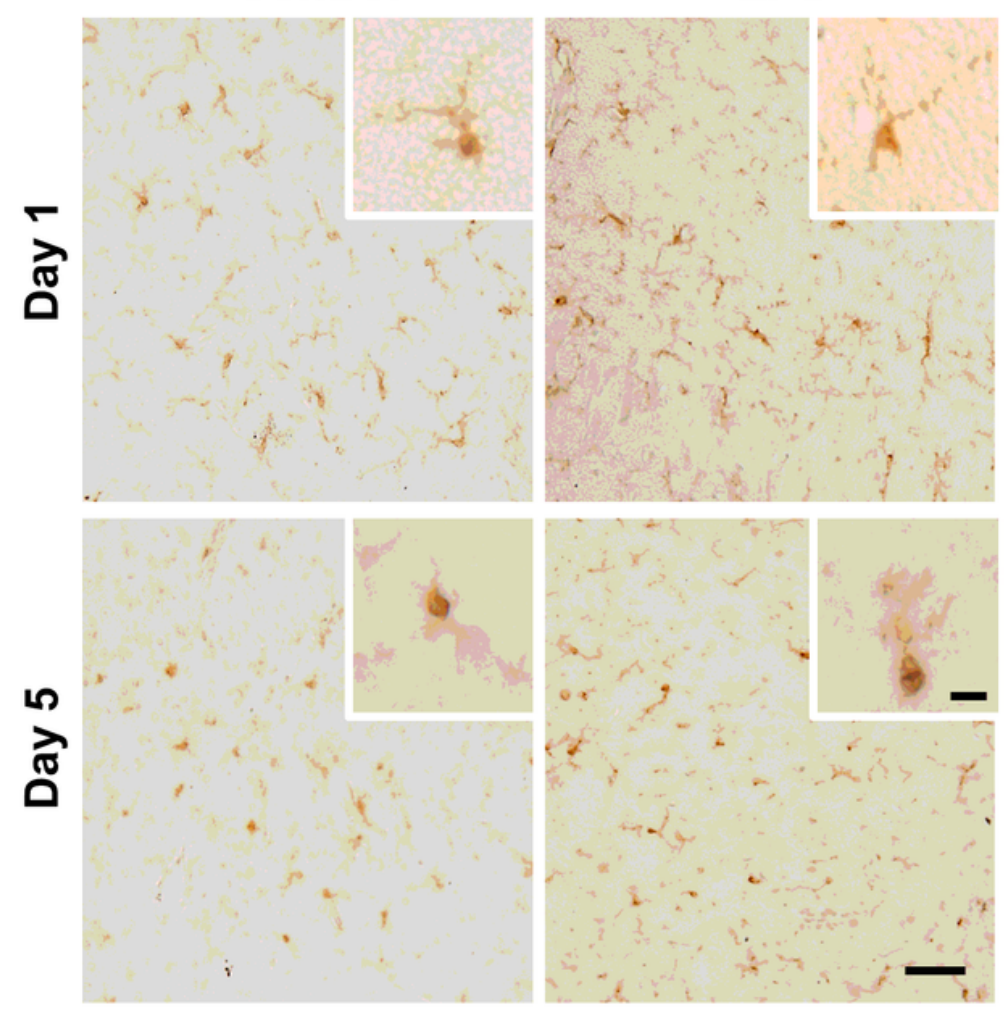

\section{Figure 4}

Intra-amniotic LPS exposure induced microglial activation in a spatiotemporal manner. (A) Quantification of the intensity of Iba1 and (B) GFAP immunoreactivity in the cortical, hippocampal and periventricular white matter (PVWM) regions at postnatal Day 1 (d1) and Day 5 (d5) in preterm pigs exposed in utero to either vehicle (control, $n=8)$ or LPS $(n=9-11)$. The values are presented as the mean \pm SEM, ${ }^{*} p<0.05$, ${ }^{\star \star} p<0.01$. (C) Representative images of Iba-1-labeled hippocampi from control- and LPS-treated pigs at birth (Day 1) and at Day 5 after exposure. Inserts: magnified view of representative individual microglial cells. Scale bar, $100 \mu \mathrm{m}$; insert, $10 \mu \mathrm{m}$. 


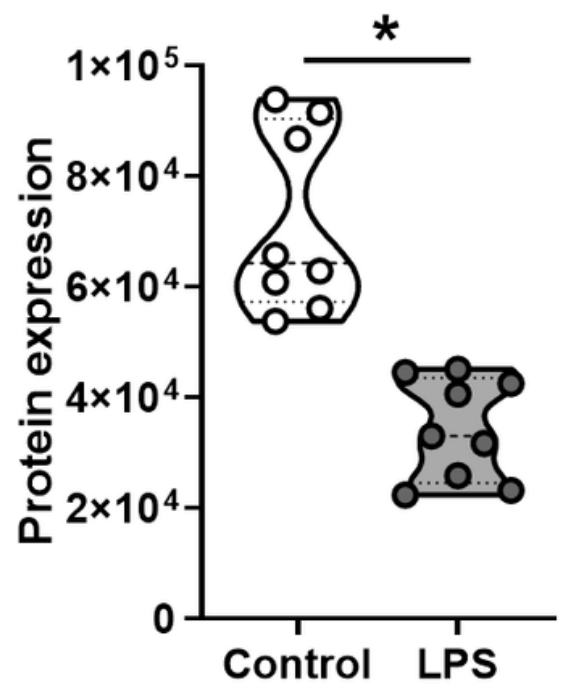

MIA3

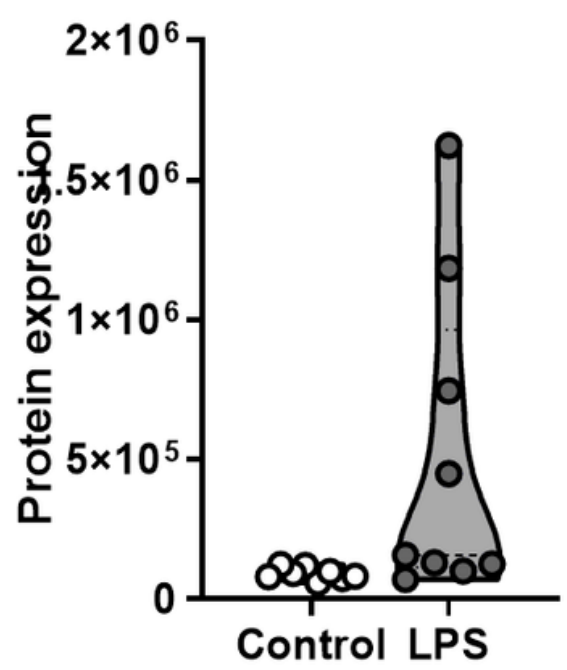

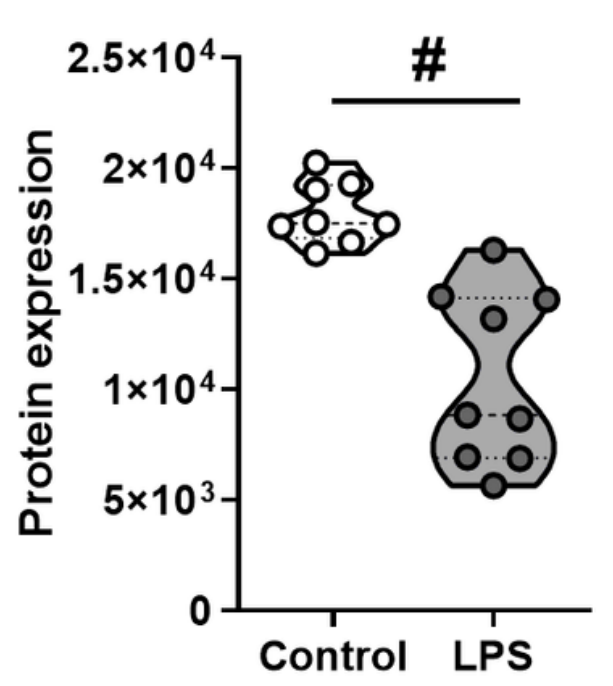

PLLP

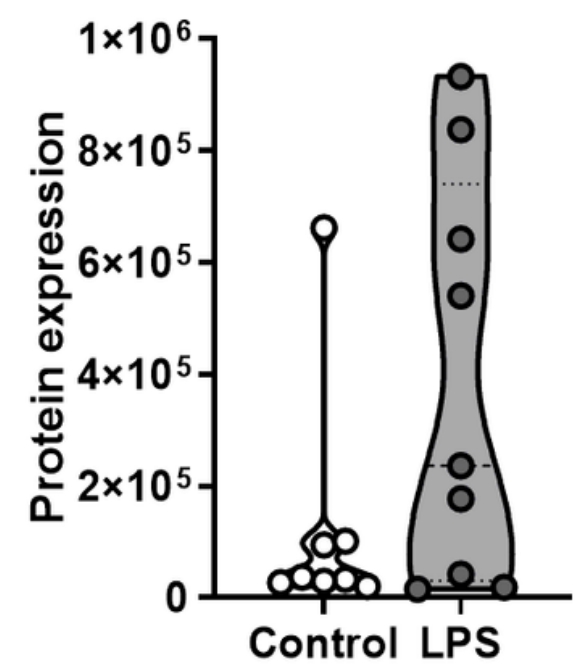

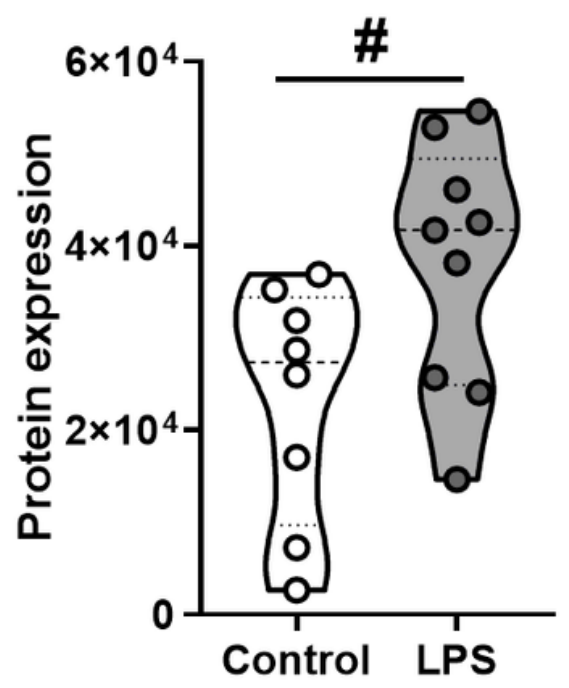

CLDN11

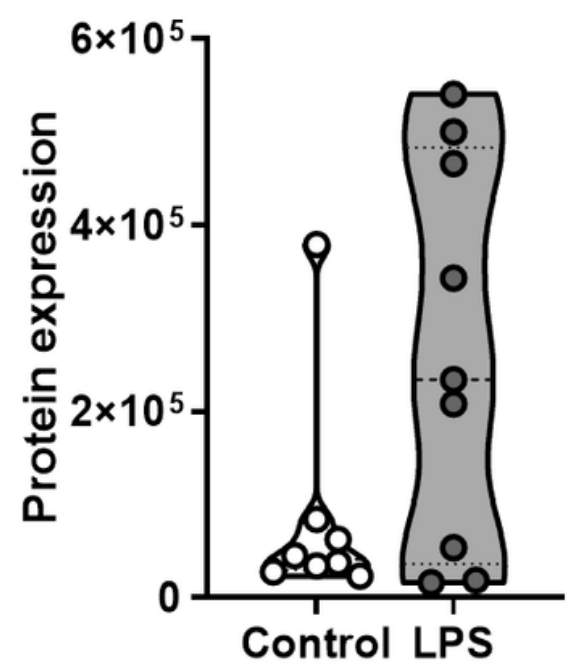

Figure 5

Antenatal inflammation-induced hippocampal protein profiling changes on P5. (A-B) The expression of the hippocampal DEPs elastin and MINPP1, which was upregulated by fetal LPS exposure, on P5. (C) The expression of the hippocampal DEP PRICKLE2, which was downregulated by fetal LPS exposure, on P5. (D-F) The expression of the MIA3, PLLP and CLDN11 proteins, which were downregulated by fetal LPS exposure, on P5. The data are presented as the mean \pm SEM. \#, $q \leq 0.01$. MINPP1: multiple inositol polyphosphate phosphatase 1; PLLP: Plasmolipin; CLD11: claudin 11; MIA3: melanoma inhibitor protein 3; PRICKLE2: prickle homolog 2. 
A

FGFR1

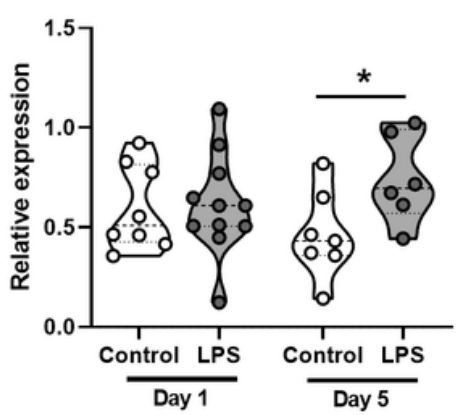

MINPP1

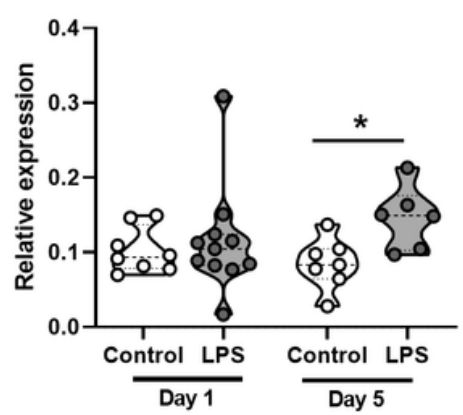

BASP1

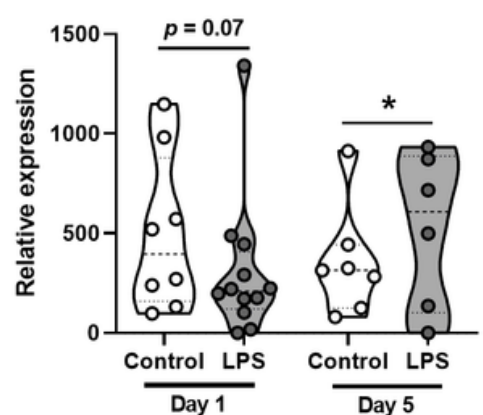

B

LBP

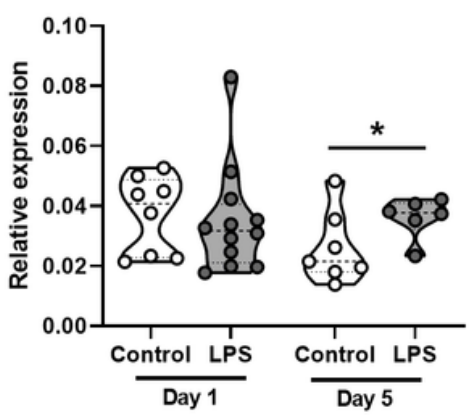

S100A9

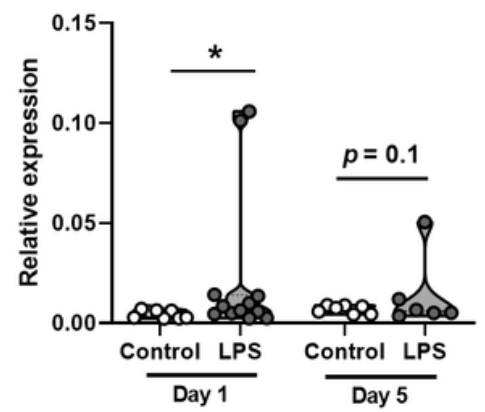

HIF1a

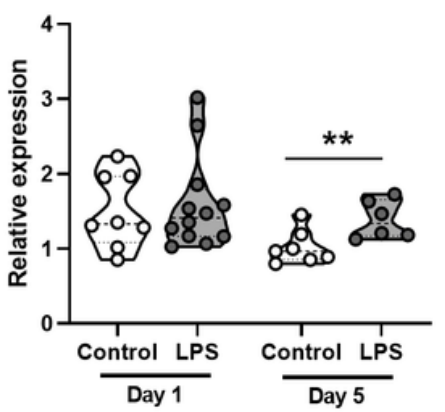

C3

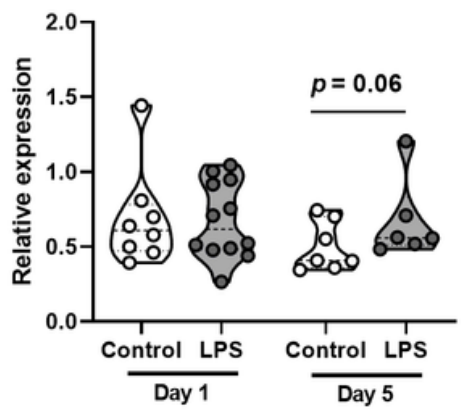

Figure 6

Intra-amniotic LPS exposure changed the expression of selected genes in the hippocampus of preterm pigs in a time-dependent manner. The values are presented as the mean $\pm \mathrm{SEM},{ }^{*} \mathrm{p}<0.05,{ }^{*} \mathrm{p}<0.01$.

\section{Supplementary Files}

This is a list of supplementary files associated with this preprint. Click to download.

- supplymenttable1.docx 